\title{
Biomarkers for the Early Detection and Progression of Alzheimer's Disease
}

\author{
Scott E. Counts ${ }^{1,2,3} \cdot$ Milos D. Ikonomovic $^{4,5,6} \cdot$ Natosha Mercado $^{1} \cdot$ Irving E. Vega $^{1}$. \\ Elliott J. Mufson ${ }^{7}$
}

Published online: 13 October 2016

(C) The American Society for Experimental NeuroTherapeutics, Inc. 2016

\begin{abstract}
The recent failures of potential disease-modifying drugs for Alzheimer's disease (AD) may reflect the fact that the enrolled participants in clinical trials are already too advanced to derive a clinical benefit. Thus, well-validated biomarkers for the early detection and accurate diagnosis of the preclinical stages of $\mathrm{AD}$ will be crucial for therapeutic advancement. The combinatorial use of biomarkers derived from biological fluids, such as cerebrospinal fluid (CSF), with advanced molecular imaging and neuropsychological testing may eventually achieve the diagnostic sensitivity and specificity necessary to identify people in the earliest stages of the disease when drug modification is most likely possible. In this regard, positive amyloid or tau tracer retention on positron emission tomography imaging, low CSF concentrations of the amyloid- $\beta$ 1-42 peptide, high CSF concentrations in total tau and phospho-tau, mesial
\end{abstract}

Elliott J. Mufson

elliott.mufson@dignityhealth.org

1 Department of Translational Science and Molecular Medicine, Michigan State University, Grand Rapids, MI, USA

2 Department of Family Medicine, Michigan State University, Grand Rapids, MI, USA

3 Hauenstein Neuroscience Center, Mercy Health Saint Mary's Hospital, Grand Rapids, MI, USA

4 Department of Neurology, University of Pittsburgh, Pittsburgh, PA, USA

5 Department of Psychiatry, University of Pittsburgh, Pittsburgh, PA, USA

6 Geriatric Research Education and Clinical Center, VA Pittsburgh Healthcare System, Pittsburgh, PA, USA

7 Department of Neurobiology and Neurology, Barrow Neurological Institute, Phoenix, AZ, USA temporal lobe atrophy on magnetic resonance imaging, and temporoparietal/precuneus hypometabolism or hypoperfusion on $18 \mathrm{~F}$-fluorodeoxyglucose positron emission tomography have all emerged as biomarkers for the progression to $\mathrm{AD}$. However, the ultimate $\mathrm{AD}$ biomarker panel will likely involve the inclusion of novel CSF and blood biomarkers more precisely associated with confirmed pathophysiologic mechanisms to improve its reliability for detecting preclinical $\mathrm{AD}$. This review highlights advancements in biological fluid and imaging biomarkers that are moving the field towards achieving the goal of a preclinical detection of $\mathrm{AD}$.

Keywords Alzheimer's disease · Mild cognitive impairment · Biomarker $\cdot$ Cerebrospinal fluid $\cdot$ Positron emission tomography $\cdot$ Amyloid

\section{Introduction}

Alzheimer's disease (AD) has an extensive preclinical stage, which is initiated 15 to 20 years prior to the emergence of clinical signs $[1,2]$. Neuropathologic examination of older people who died with a clinical diagnosis of no cognitive impairment (NCI) or mild cognitive impairment (MCI) often reveal similar pathological signatures to those with frank $A D$ [3-7], suggesting a heterogeneous asymptomatic phase of $A D$ that varies in elderly individuals. These concepts have energized the field to develop a biomarker for identifying individuals in the earliest preclinical stages of $\mathrm{AD}$, to facilitate early intervention and to delay or perhaps even prevent the onset of clinical symptoms. Moreover, biomarkers for $\mathrm{AD}$ progression may also have clinical utility for tracking the efficacy of potential disease-modifying therapies. 
The National Institute on Aging-Alzheimer's Association (NIA-AA) developed new working criteria for using a panel of prognostic fluid and imaging biomarkers to determine the likelihood of AD pathology and the staging of preclinical AD and the progression to prodromal and then clinical $\mathrm{AD}[1,8]$, which included cerebrospinal fluid (CSF) amyloid- $\beta(\mathrm{A} \beta)_{42}$, amyloid positron emission tomography (PET), CSF total tau, threonine 181 (T181) phospho-tau, mesial temporal lobe (MTL) atrophy on magnetic resonance imaging (MRI), and tempoparietal/precuneus hypometabolism or hypoperfusion on 18F-fluorodeoxyglucose (FDG)-PET (Fig. 1) [1, 9]. In general, findings to date have suggested that cerebral amyloidosis, as measured by increased amyloid PET signal and lower

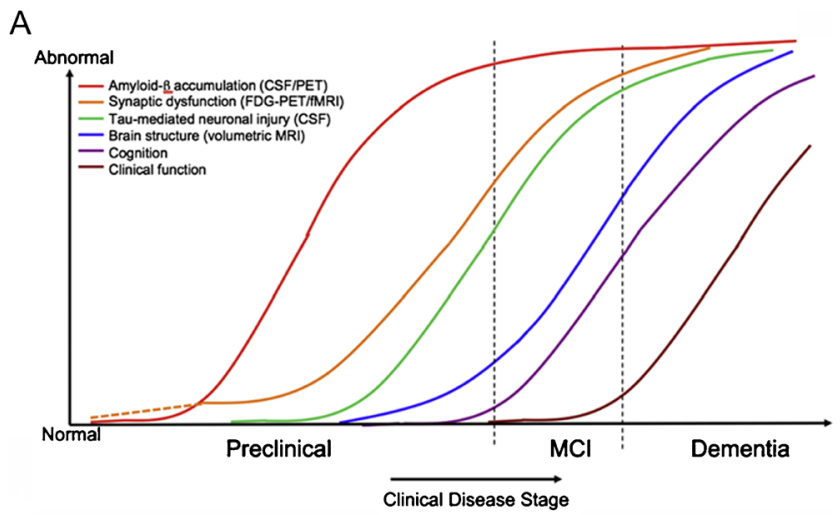

B

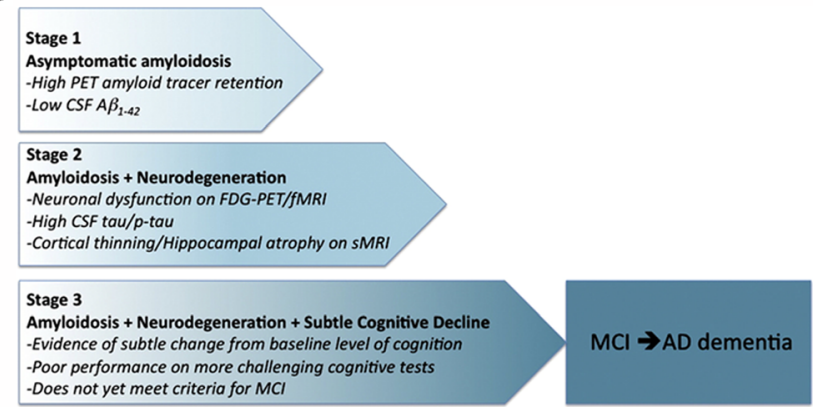

Fig. 1 Current models for Alzheimer's disease (AD) progression biomarkers. (A) A revised hypothetical model of biomarkers identifying preclinical AD [1], as originally proposed by Jack et al. [9]. In this model, amyloid $\beta(\mathrm{A} \beta)$ changes (red) as identified by cerebrospinal fluid (CSF) $\mathrm{A} \beta_{42}$ assay or positron emission tomography (PET) amyloid imaging precede markers for synaptic dysfunction (orange), as evidenced by fluorodeoxyglucose (FDG)-PET and functional magnetic resonance imaging (fMRI). These alterations are closely associated with increased CSF tau (green), which serves as a surrogate for neuronal injury. The dashed orange line indicates that synaptic dysfunction may be detectable in apolipoprotein $\mathrm{E}$ (ApoE) $\varepsilon 4$ carriers before detectable $\mathrm{A} \beta$ deposition. Brain atrophy on structural MRI (sMRI; blue) and subtle decline in cognitive function (purple) mark the transition from preclinical $\mathrm{AD}$ to mild cognitive impairment (MCI). (B) Hypothetical staging of preclinical AD. Stage 1 and 2 individuals may not progress to stage 3, whereas stage 3 individuals may be more likely to progress to MCI and AD. Reprinted from Alzheimer's and Dementia, Sperling et al., Toward defining the preclinical stages of Alzheimer's disease: Recommendations from the National Institute on Aging-Alzheimer's Association workgroups on diagnostic guidelines for Alzheimer's disease, 7 (3): 280-292, with permission from Elsevier
CSF levels of $A \beta_{42}$, precedes markers of neurodegeneration and synaptic dysfunction (e.g., FDG-PET, MRI, and CSF tau) prior to the onset of subtle cognitive impairment related to AD. More specifically, loss of hippocampal volume on MRI and the ratio of CSF $A \beta_{42}$ to total tau or phospho-tau are predictive of longitudinal changes in cognitive measures in the face of mounting AD pathology and its clinical sequelae [9-13]. In addition, arterial spin labeling MRI is used to examine the influence of changes in resting cerebral blood flow, as well as blood oxygenation level-dependent signal response in relation to PET-derived regional amyloid load [14, 15], or to memory encoding in the MTL [16]. Finally, new advances in tau PET imaging and novel fluid biomarkers hold promise to increase biomarker reliability. In fact, tau PET imaging studies suggest that tau accumulation may track better with cognitive decline compared with $\mathrm{A} \beta$ deposition in people with $\mathrm{AD}$ [17-19]. The combinatorial use of fluid and imaging biomarkers with neuropsychological testing may eventually achieve the diagnostic sensitivity and specificity necessary to identify people in the earliest stages of the disease when modification is most likely possible. In this regard, advancing biomarker research to clinical diagnostic settings will be critical for recruiting appropriate individuals who meet inclusion criteria for clinical trials. This article reviews the latest advancements in biological fluid and imaging biomarkers that are moving the field towards achieving this goal.

\section{CSF Core Biomarkers}

The CSF is in direct contact with the extracellular space of the brain and serves as a substrate for biochemical changes related to brain pathology. With respect to $\mathrm{AD}$, the current core CSF biomarkers-A $\beta_{42}$, total tau, and phospho-tau (phosphorylated specifically at residue T181) —are assayed by enzyme-linked immunosorbent assay (ELISA) or multiplexed assays as surrogates for mounting neuropathologic plaque and neurofibrillary tangle (NFT) lesions. Hence, it is generally thought that lower CSF $\mathrm{A} \beta_{42}$ levels correlate with accumulating plaque deposition and higher CSF tau levels correlate with neuronal injury during AD progression.

Early CSF biomarker studies were cross sectional and focused on differentiating AD from control patients. After it was found that $A \beta$ is generated as a soluble protein during normal cellular metabolism and secreted into the CSF [20], biomarker research found that $\mathrm{CSF}$ total $\mathrm{A} \beta$ was decreased slightly in $\mathrm{AD}[21,22]$. However, as these initial findings did not discriminate between different $A \beta$ isoforms, there was considerable overlap between patients with $\mathrm{AD}$ and controls, while other studies reported no change in CSF total $A \beta$ in AD [23]. As the $A \beta_{42}$ isoform was found to be more prone than $\mathrm{A} \beta_{40}$ to aggregate at physiologic $\mathrm{pH}$ and form the nidus of 
senile plaques $[24,25]$, subsequent analysis of CSF $A \beta_{42}$ used $\mathrm{C}$-terminal-specific antibodies. These early reports consistently showed a $\sim 50 \%$ decrease in $A \beta_{42}$ in moderate AD compared with age-matched control subjects [26-29].

The first study of CSF total tau as a biomarker for AD used a pan-tau antibody that recognized both unphosphorylated and phosphorylated tau, and reported an $\sim 1000 \%$ increase in CSF tau from older patients with $\mathrm{AD}$ compared with younger adult controls [30]. Subsequent age-matched studies using tau monoclonal antibodies that detect all isoforms of tau independently of phosphorylation state found an 200\% to $300 \%$ increase in total tau in $\mathrm{AD}$ [31-33]. ELISA methods were also developed for phospho-tau as a putative readout of tau pathology by targeting epitopes associated with NFTs, including threonine 181, threonine 231, and serine $396+404$ (the PHF-1 epitope), among others, with observations of up to $\sim 300 \%$ increases in these phospho-tau moieties in the CSF of patients with AD [34-36]. Blennow [37] evaluated the sensitivity and specificity of core CSF biomarkers for differentiating $\mathrm{AD}$ from controls. CSF $\mathrm{A} \beta_{42}$ demonstrated a mean sensitivity of $86 \%$ and a mean specificity of $89 \%$. By contrast, total tau yielded a mean sensitivity of $81 \%$ and a mean specificity of $91 \%$, whereas the diagnostic accuracy of multiple forms of phospho-tau also yielded a mean sensitivity of $81 \%$ and a mean specificity of $91 \%$ [37]. Moreover, combining measurements of $A \beta_{42}$ and tau concentrations in CSF improved diagnostic potential. For example, the CSF ratio of phospho-tau (T181) to $\mathrm{A} \beta_{42}$ was found to be superior to either measure alone for identifying AD among controls and other neurologic diseases, with a sensitivity of $86 \%$ and specificity of $97 \%$ [38]. Another report revealed a sensitivity of $96 \%$ and specificity of $86 \%$ using the CSF ratio of total tau to $A \beta_{42}$ [39]. While $A \beta_{42}$ demonstrates good sensitivity for differentiating $\mathrm{AD}$ from nondemented subjects, combining CSF A $\beta_{42}$ and tau measures for the differential diagnosis of $\mathrm{AD}$ appears to mitigate some of the nonspecific biochemical characteristics of $A \beta_{42}$, which is also reduced in Creutzfeldt-Jakob disease, multiple system atrophy, Lewy body dementia (LBD), frontotemporal dementia (FTD), vascular dementia, amyotrophic lateral sclerosis, and neuroinflammation, in addition to AD [40, 41]. However, CSF phospho-tau levels are particularly useful in differentiating AD from other dementias such as LBD, FTD, and vascular dementia with more than $80 \%$ specificity [42].

CSF biomarker development naturally extended to longitudinal studies and the utility of $\mathrm{A} \beta_{42}$, total tau, and phosphotau for predicting conversion from $\mathrm{NCI}$ to $\mathrm{MCI}$ and to $\mathrm{AD}$. In this regard, high CSF total tau and low CSF A $\beta_{42}$ was found in $90 \%$ of $\mathrm{MCI}$ cases that progressed to $\mathrm{AD}$ compared with $10 \%$ of stable MCI cases [43]. Likewise, high CSF phosphotau (T231) was also found in MCI cases that progressed to AD compared with stable MCI cases and correlated with decline on neuropsychological testing $[44,45]$. Several additional longitudinal studies of clinically well-characterized cohorts validated the concept that the CSF core biomarkers could be used to help predict likelihood of conversion. Notably, Hansson et al. [46] showed that the combination of high total-tau with a low $\mathrm{A} \beta_{42} /$ phospho-tau (T181) ratio at baseline yielded $95 \%$ sensitivity and $87 \%$ specificity for the detection of incipient AD. Fagan et al. [10] compared baseline CSF samples from 139 patients with Clinical Dementia Rating (CDR) scores of CDR 0 (cognitively normal or NCI), CDR 0.5 (MCI or very mild AD), or CDR 1 (mild AD) with followup clinical assessments [10]. Cox proportional hazard models adjusted for age, sex, education, and $A P O E$ genotype revealed that participants with CSF total tau/A $\beta_{42}$ and phospho-tau (T181)/A $\beta_{42}$ significantly predicted conversion from CDR 0 to $\mathrm{CDR}$ greater than 0 , with higher ratios predicting a faster rate of conversion than those with low ratios [10]. Interestingly, the tau $/ \mathrm{A} \beta_{42}$ ratios were similar in CDR 0.5 (MCI) and CDR 1 (mild AD), underscoring the diagnostic potential of the biomarker for identifying prodromal disease. A more recent analysis of CSF samples from patients in the Amsterdam Dementia Cohort showed that the tau $/ \mathrm{A} \beta_{42}$ ratio was the most robust combination for predicting dementia due to $\mathrm{AD}$ in subjects with MCI [47].

Given the effects of apolipoprotein E4 (ApoE4) gene dosage on the risk of $\mathrm{AD}$ and age at dementia onset [48], several groups have evaluated biomarker trajectories as a function of $\varepsilon 4$ allele number, with varying agreement [49-53]. Most recently, 2 studies examined the effects of ApoE4 on longitudinal CSF core biomarkers within cohorts of cognitively normal middle-to-older-aged subjects. Sutphen et al. [52] found that $\varepsilon 4$ homozygotes yielded among the lowest CSF A $\beta_{42}$ levels, whereas $\varepsilon 4$ noncarriers were associated with the highest CSF $\mathrm{A} \beta_{42}$ levels, with heterozygotes falling in the middle range. Moreover, longitudinal increases for total tau and total tau/ $\mathrm{A} \beta_{42}$ and decreases in cognitive function appeared to overlap to a greater extent in $\varepsilon 4$ carriers than in noncarriers [52]. Likewise, Toledo et al. [53] found that $\varepsilon 4$ carriers showed higher CSF tau and lower $A \beta_{42}$ values than $\varepsilon 3 / \varepsilon 3$ patients, with the largest effect observed for $A \beta_{42}$. Whereas $A \beta_{42}$ values remained stable up to the beginning of the seventh decade in healthy controls without any $\varepsilon 4$ alleles, $A \beta_{42}$ levels of healthy controls with 1 or $2 \varepsilon 4$ alleles showed a decrease beginning during the fifth decade of life and plateaued at the middle of the eighth decade. Hence, the ApoE gene dosage risk factor for AD may be reflected in CSF biomarkers - particularly low $\mathrm{A} \beta_{42}$ levels - in middle age as a potential signal for the onset of preclinical AD.

The progression from single-center studies to multicenter efforts were initially faced with problems related to intersite differences such as CSF collection, storage methods and assay platforms [54]. For example, a 12-center study of 750 individuals with NCI, MCI, and AD recruited in Europe and the USA found that the combination of CSF $\mathrm{A} \beta_{42} /$ phospho-tau 
(T181) and total tau identified incipient AD within the MCI group with fairly good accuracy, but with lower sensitivity $(83 \%)$ and specificity $(72 \%)$ than reported for single-center studies [11]. The $\mathrm{A} \beta_{42}$ assay had considerable intersite variability, and the authors highlighted the need for standardization of analytical techniques and clinical diagnostics [11]. Indeed, standardization efforts became a major focus for multisite studies, including the AD Neuroimaging Initiative (ADNI). Within the Biomarker Core of ADNI, efforts were made to standardize the analysis of all collected baseline CSF samples by using the same multiplexed xMAP bead-based platform (Luminex, Austin, TX, USA) with $\mathrm{A} \beta_{42}$, phosphotau (T181), and total tau monoclonal antibodies provided in the INNO-BIA Alz Bio3 immunoassay kit (Innogenetics, Ghent, Belgium). The initial utility of the approach was demonstrated by comparing cut-off values of $\mathrm{A} \beta_{42}$, phospho-tau (T181), and total tau in an ADNI clinical cohort of control participants, and subjects with $\mathrm{MCI}$ and $\mathrm{AD}$ and comparing those values with CSF from independent, autopsy confirmed control and AD cases [55]. The baseline CSF profile for total $\operatorname{tau} / \mathrm{A} \beta_{42}$ was detected in 33 of 37 ADNI participants with MCI who converted to probable AD during the first year of the study. By contrast, $A \beta_{42}$ cut-off values derived from the ADNI cohort was the most sensitive biomarker for AD in the autopsy cohort, with a receiver operating characteristic area under the curve (AUC) of 0.913 and sensitivity for AD detection of $96.4 \%$ [55]. Using this same standardized procedure, Shaw et al. [56] analyzed within-site and intersite assay reliability across 7 ADNI centers using aliquots of CSF from normal controls and patients with AD. Each center performed 3 analytical runs using separate fresh aliquots of each CSF sample examined and data were analyzed using mixedeffects modeling to determine assay precision. The coefficient of variation was $5.3 \%$ for $A \beta_{42}, 6.7 \%$ for total tau, $10.8 \%$ for phospho-tau within centers, and $17.9 \%$ for $A \beta_{42}, 13.1 \%$ for total tau, and $14.6 \%$ for phospho-tau between centers [56]. More recently, Toledo et al. [57] investigated biomarker changes in ADNI controls, and subjects with MCI and AD across multiple centers over a 4-year period using standardized procedures [57]. In this study, clinical diagnosis was associated with abnormal baseline levels of both $A \beta_{42}$ and total tau, or with abnormal phospho-tau (T181) levels alone. Moreover, low baseline $\mathrm{A} \beta_{42}$ predicted greater increases in phospho-tau (T181) levels on follow-up, whereas neither baseline total tau nor phospho-tau was associated with an $\mathrm{A} \beta_{42}$ decrease during follow-up, suggesting that changes in $\mathrm{A} \beta_{42}$ levels precede tau levels [57]. Notably, the longitudinal stability of these biomarkers varied in patients with normal baseline levels: 1 group remained stable over time, whereas the other had decreasing $A \beta_{42}$ and increasing phospho-tau (T181) levels over time. When the stable population was excluded from analysis, the time taken to reach cut point levels of biomarkers was significantly shortened. Hence, longitudinal analysis of CSF biomarkers revealed substantial cohort heterogeneity and the lack of a clear association between level changes and cognitive status, at least over a span of 4 years. However, the suggestion that changes in $A \beta_{42}$ levels precede tau levels reflects a similar finding in a European cohort showing that levels of $\mathrm{A} \beta_{42}$ are already fully decreased at least 5 to 10 years before conversion to $\mathrm{AD}$, whereas increases in the tau markers appear later for converters [58]. However, as proposed by the new working criteria for AD, the appearance of elevated baseline CSF tau and other markers of neurodegeneration may reliably predict the onset of cognitive impairment in preclinical subjects [10, 59]. Hence, despite lingering pre- and post-analytic issues of intersite variability, the CSF core biomarkers developed to date are useful for the early diagnosis of $\mathrm{AD}$ and prediction of disease progression (Fig. 2). Altered baseline levels in these markers, used in combination with imaging and other novel fluid biomarkers, as discussed below, may be clinically beneficial for the reliable identification of preclinical and prodromal disease for the efficient design of drug intervention clinical trials (Fig. 1).

\section{Novel CSF Biomarkers}

Despite the promise for CSF core biomarkers for the identification of presymptomatic $\mathrm{AD}$, the inherent heterogeneity in the progression of mounting plaque and tangle load over time between patients, as well as the presence of mixed pathologies and different comorbidities, highlight the need to augment the CSF core biomarkers with novel proteins to improve diagnostic accuracy in longitudinal studies [60-62]. A growing list of candidate biomarkers for $\mathrm{AD}$ derived from the CSF has been proposed, including apolipoprotein isoforms [63, 64], brainderived neurotrophic factor [65], prostaglandin D2 synthase:transthyretin dimers [66], synuclein isoforms [67, 68], ubiquitin [69, 70], SNAP-25 [71], neurogranin [72-74], visinin-like protein 1 (VILIP-1) and chitinase-3-like protein 1 (YKL-40) [52, 75, 76], and the neurofilament light chain (NFL) [77-79]. In particular, a longitudinal CSF analysis of the postsynaptic protein, neurogranin, in 378 healthy controls and subjects with MCI and AD revealed significantly higher neurogranin in $\mathrm{MCI}$ converters and patients with AD compared with controls and MCI nonconverters [74]. Neurogranin was strongly correlated with CSF tau but not $\mathrm{A} \beta_{42}$ levels, and high neurogranin levels were significantly associated with deterioration in cognitive performance, hippocampal volume on MRI, and cortical glucose metabolism on FDG-PET in healthy controls [74]. Likewise, CSF levels of the neuronal calcium sensor VILIP-1 differentiated CDR 0.5 to 2 from CDR 0 controls and individuals with other dementias such as LBD and FTD and correlated with CSF tau, phospho-tau (T181), and brain volume. CSF VILIP-1/A $\beta_{42}$ predicted future cognitive impairment at 
A

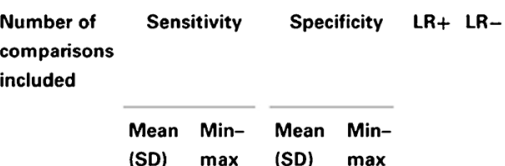

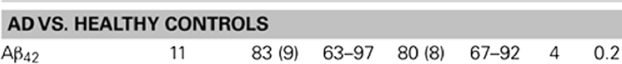

$\begin{array}{llllllll}A \beta_{42} & 11 & 83(9) & 63-97 & 80(8) & 67-92 & 4 & 0.2 \\ \text { T-tau } & 12 & 78(9) & 61-91 & 82(14) & 53-97 & 4 & 0.3\end{array}$

$\begin{array}{llllllll}\text { p-tau } & 12 & 78(10) & 61-89 & 77(18) & 37-92 & 3 & 0.3\end{array}$

$\begin{array}{llllllll}\text { Combination } \quad 25 & 87(6) & 70-98 & 84(9) & 53-97 & 5 & 0.2\end{array}$ AD VS. OTHER DEMENTIAS

$\begin{array}{lllllllll}A \beta_{42} & 5 & 85(5) & 82-95 & 61(24) & 22-80 & 2 & 0.2\end{array}$

$\begin{array}{llllllll}T \text {-tau } & 4 & 75(14) & 61-92 & 71(22) & 40-93 & 3 & 0.4\end{array}$

$\begin{array}{llllllll}\text { p-tau } & 4 & 80(6) & 77-88 & 78(15) & 56-88 & 4 & 0.3\end{array}$

$\begin{array}{llllllll}\text { Combination } & 19 & 86(10) & 67-100 & 78(14) & 36-97 & 4 & 0.2\end{array}$

MCI-CVS. MCl-S

$\begin{array}{llllllll}A \beta_{42} & 9 & 79(14) & 55-91 & 63(20) & 36-96 & 2 & 0.3\end{array}$

$\begin{array}{llllllll}T-\text { tau } & 9 & 76(12) & 60-88 & 58(17) & 39-88 & 2 & 0.4\end{array}$

$\begin{array}{llllllll}\text { p-tau } & 7 & 78(9) & 64-85 & 56(18) & 30-90 & 2 & 0.4\end{array}$

$\begin{array}{llllllll}\text { Combination } & 19 & 84(10) & 57-98 & 63(19) & 36-95 & 2 & 0.3\end{array}$

$A D$, Alzheimer's disease; $M C l$, mild cognitive impairment (MCl.C: $\mathrm{MCl}$ converters, MCl-S: MCl-stables); SO, standard deviation; LR+, positive likelihood ratio; $L R-$, negative likelihood ratio; sensitivity and specificity values are expressed in percentages.

Fig. 2 Summary of cerebrospinal fluid (CSF) biomarker diagnostic performance. (A) Sensitivity, specificity, and likelihood ratios of CSF core biomarkers based on primary studies published after the introduction of new criteria recommended by the National Institute on Aging-Alzheimer's Association workgroups [96].* (B) Head-to-head CSF biomarker performance based on average Alzheimer's disease (AD) to control ratios. Biomarkers are differentiated based on significant differences with good effect sizes (green), significant differences with moderate effect sizes (purple), or nonsignificant or

least as well as the tau/A $\beta_{42}$ ratios, and VILIP-1 and VILIP-1/ $A \beta_{42}$ accurately predicted the presence or absence of amyloid PET positivity, regardless of clinical diagnoses, suggesting its augmentative utility for preclinical AD screening [80]. NFL has also emerged as a potential surrogate marker for disease pathogenesis related to axonal pathology. In this regard, a recent study using cases from the ADNI cohort showed that CSF NFL was higher in subjects with MCI and AD than individuals with NCI, and that higher NFL concentration was associated with faster whole-brain and hippocampal atrophy, white matter intensity changes, and cognitive deterioration over time [79]. Another potential CSF marker for disease progression is pro nerve growth factor (proNGF), which is the predominant NGF moiety in brain that displays dual survival/apoptotic properties and is increased in $\mathrm{MCI}$ and $\mathrm{AD}$ postmortem brain tissue [81-83]. Our group recently showed that CSF levels of proNGF were higher in subjects with amnestic MCI and mild $\mathrm{AD}$, as well as CDR 0.5 and 1 , than in people with NCI or CDR 0, respectively [84]. Increasing CSF proNGF was significantly associated with cognitive deterioration, and the combination of proNGF/A $\beta_{42}$ performed better than tau $/ \mathrm{A} \beta_{42}$ for distinguishing amnestic MCI from controls [84]. Collectively, these novel CSF biomarkers could reflect molecular changes associated with disease pathogenesis, including deficiencies in synaptic function and cell survival factors.

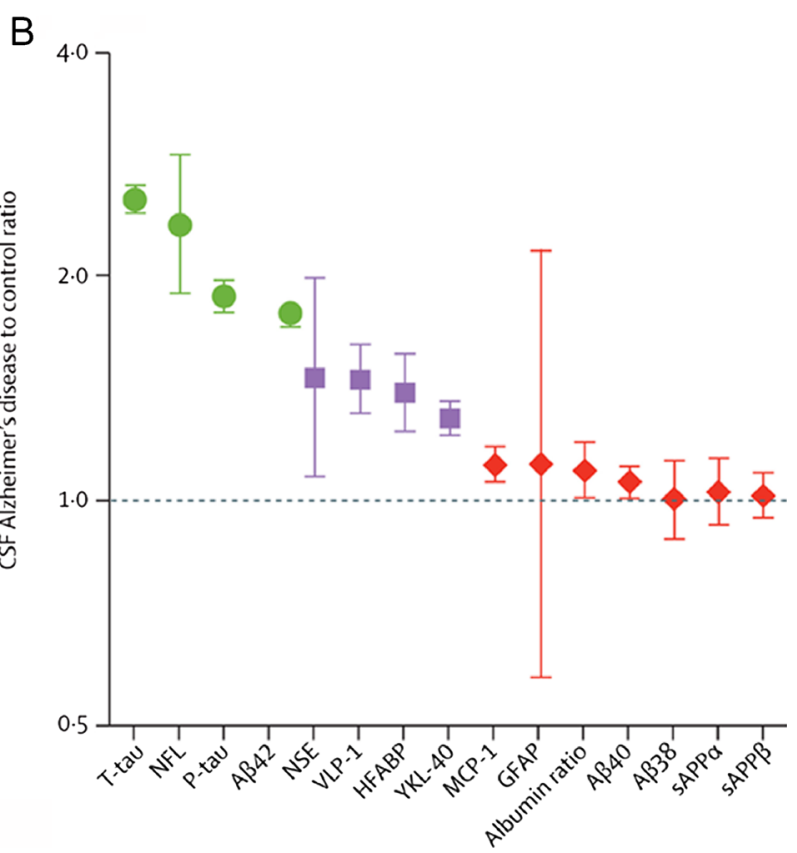

significant with minor effect sizes (red) [97]*** Reprinted from Frontiers in Aging Neuroscience 6, 47, Ferreira et al., Meta-review of CSF core biomarkers in Alzheimer's disease: the state-of-the-art after the new revised diagnostic criteria, pp. 1-24, 2014 (Open Access). **Reprinted from The Lancet Neurology, Olsson et al., CSF and blood biomarkers for the diagnosis of Alzheimer's disease: a systematic review and meta-analysis, doi:10.1016/S1474-4422(16)00070-3 2016, with permission from Elsevier.

With respect to inflammatory pathways, the proinflammatory chitinase YKL-40, which was isolated initially in a proteomic screen, displayed significantly higher levels in CDR 0.5 and 1 compared with CDR 0 individuals in a discovery and validation cohort, with $\mathrm{CSF}$ YKL- $40 / \mathrm{A} \beta_{42}$ ratio predicting the conversion from $\mathrm{CDR} 0$ to $\mathrm{CDR}>0$, as well as total tau/A $\beta 42$ and phospho-tau $(\mathrm{T} 181) / \mathrm{A} \beta_{42}$ [85]. Other notable promising CSF candidate markers include protein modulators of the endosomal-autophagy-lysosomal system [86], which may reflect the major disturbances found in these pathways in MCI and AD [87-89]; protein and lipid markers of oxidative stress in MCI and AD [90-92]; and alterations in microRNA profiles that may reflect underlying dysregulation of amyloid and tau pathways [93-95]. Two recent metareviews $[96,97]$ provide a current state of the field with respect to the utility of CSF core (Fig. 2A) and novel (Fig. 2B) biomarkers for identifying people at risk for dementia. As the most rigorously tested surrogates for $\mathrm{AD}$ pathogenesis, CSF amyloid-beta $A \beta$ and tau levels will continue to help refine a reliable composite biomarker along with imaging and cognitive parameters. Ultimately, the addition of novel biomarkers to augment the differential diagnosis of $\mathrm{AD}$ and other dementias in their preclinical and prodromal stages may provide a front-line screen for early intervention and optimal subject recruitment for clinical trials. 


\section{Molecular Neuroimaging Biomarkers}

The development of PET radioligands for the in vivo detection of fibrillary $A \beta$ deposits and intracellular tau aggregates has provided a significant advance in biomarker development, complementing CSF studies and expanding our knowledge of how early amyloid plaques and NFTs begin to develop in the preclinical phases of $\mathrm{AD}$. Although the relative role that these hallmark AD pathologies play in the onset of synaptic loss, neuronal cell death, and clinical symptoms of MCI and early $\mathrm{AD}$ remain to be determined, it is becoming evident that they precede clinical onset by years or decades [1].

Although amyloid PET and CSF biomarkers can identify early AD with similar accuracy [98], highly sensitive imaging radioligands used in combination with other novel AD biomarkers will be critical for timely initiation of therapy trials in pathological aging, $\mathrm{MCI}$, and early $\mathrm{AD}$.

Pittsburgh compound B [PiB; [C-11]6-OH-BTA-1; [N-methyl-11C]2-(4'-methylaminophenyl)-6-hydroxybenzothiazole] is the most widely used amyloid imaging agent and the first $A \beta$ selective radiotracer to differentiate AD from NCI by PET [ 99 , $100]$. PiB binds with a high affinity to $\beta$-sheet structured amyloid aggregates [101], and owing to its good brain penetrance and fast clearance is suitable for PET imaging [102]. In NCI controls, PiB PET retention is typically low in cortical, subcorti$\mathrm{cal}$, and cerebellar regions, while in $\mathrm{AD}$ it is high in cortical regions displaying $\mathrm{A} \beta$ plaques at postmortem evaluation [103]. With respect to CSF core biomarkers, a strong concordance between PiB-PET and CSF $A \beta_{42}$ was seen in mixed cohorts of $\mathrm{NCI}$ and $\mathrm{AD}$ [104, 105], or NCI, MCI, and AD [106], with no correlation between PiB-PET and CSF tau [104]. These findings were corroborated in other cohorts with NCI [107], MCI [108, 109] and AD [105]. Some longitudinal studies suggested that amyloid PET may be more sensitive than CSF A $\beta_{42}$ in identifying subjects with $\mathrm{MCI}$ who will convert to $\mathrm{AD}$. Forsberg et al. [108] reported that all those with $\mathrm{MCI}$ who converted to $\mathrm{AD}$ had high PiB PET retention, but less than half of them had pathological CSF A $\beta_{42}$. In another study, $87 \%$ of MCI cases had high PiB retention, with only $53 \%$ having pathological CSF A $\beta_{42}$ [109]. A clinical-pathological study of a PiB-negative patients with $\mathrm{NCI}$ reported that 12 months after PET scan there was a decrease in CSF A $\beta_{42}$ and a slight increase in CSF tau and p-tau concentrations, and 6 months later the individual transitioned to $\mathrm{MCI}$ [110]. In this case, brain autopsy revealed primarily diffuse $A \beta$ plaques in the neocortex, suggesting that compared with PiBPET, CSF $A \beta_{42}$ is a more sensitive biomarker for detection of AD pathology [110].

Postmortem brain studies indicate that PiB binding is most prominent in classic neuritic plaques and vascular $\mathrm{A} \beta$ deposits [cerebral amyloid angiopathy (CAA)] [111-114], yet it does not bind to NFTs or non-AD neuropathology [112, 115-118]. While both $\mathrm{A} \beta$ plaques and $\mathrm{CAA}$ can contribute to PiB- retention in vivo, $\mathrm{CAA}$ is most frequent in the occipital lobe, which is less affected with plaques when compared with other cortical regions [119, 120]. Johnson et al. [119] reported that all nondemented subjects diagnosed with clinically probable CAA and all AD subjects were PiB-positive. Global cortical $\mathrm{PiB}$ retention in CAA was greater relative to $\mathrm{NCI}$ cases, and lower than in $\mathrm{AD}$; however, the occipital-to-global $\mathrm{PiB}$ ratio was greater in $\mathrm{CAA}$ than in $\mathrm{AD}$, similar to other $\mathrm{CAA}$ cohorts [121]. An autopsy evaluation of a PiB positive patient with mild $\mathrm{AD}(\mathrm{CDR}=1$; Mini-Mental State Examination score $=$ 25 ) and a clinical diagnosis of LBD found numerous neocortical diffuse $A \beta$ plaques but only rare cored plaques and severe CAA [111]. These mixed results support the need for postmortem evaluation of PiB-PET-imaged brains for validating radioligand sensitivity and specificity, and for estimating the threshold level of underlying pathology for PET positivity. Moreover, the presence of $\mathrm{A} \beta$ deposits in $\mathrm{PiB}$ negative patients with $\mathrm{NCI}$ and $\mathrm{MCI}$ brings into question the sensitivity of PiB for detecting fibrillary A $\beta[110,117,122]$. Several studies used postmortem brain tissue analysis and in vitro $[\mathrm{H}-3] \mathrm{PiB}$ binding to validate PiB's utility in quantifying fibrillar $A \beta$ load and to distinguish among NCI, MCI, and AD. [H-3]PiB binding in the precuneus cortex was significantly higher in AD compared with NCI and MCI groups, and greater [H-3]PiB binding levels correlated strongly with a more severe CERAD (Consortium to Establish a Registry for Alzheimer's Disease) pathology scores and antemortem cognitive impairment [123, 124]. In other studies, [H-3]PiB binding in multiple brain regions was able to distinguish between clinical categories, and correlated with concentrations of fibrillar $\mathrm{A} \beta$ by ELISA $[125,126]$.

About $10 \%$ to $20 \%$ of patients with clinical AD are $\mathrm{PiB}$ negative, in agreement with autopsy reports, suggesting that they may have been clinically misdiagnosed $[4,100]$. In a study using [F-18]florbetapir PET imaging, amyloid PETnegative individuals with $\mathrm{AD}$ and $\mathrm{MCI}$ were more likely to be ApoE4-negative, exhibit lower CSF tau concentrations, and perform better on longitudinal cognitive testing, while amyloid PET-negative subjects with MCI also had milder hippocampal atrophy and hypometabolism [127]. It is also well established that $20 \%$ to $30 \%$ of NCI subjects are PiB positive [99, 118, 128-132], consistent with autopsy evidence of significant AD pathology in NCI cases [7, 133, 134]. This incidence increases up to $65 \%$ in those aged $>80$ years [135]. However, these observations are influenced by a study center's threshold for defining amyloid positivity, its clinical definition of "cognitively normal", and ApoE genotype status. ApoE4 is associated with higher PiB PET retention in elderly NCI [131, 136], while in people with MCI it confers an increased likelihood of converting to $\mathrm{AD}[137,138]$. Compared with noncarriers, ApoE4-positive patients with a $\mathrm{PiB}$ negative scan have more than double the rate of progression to $\mathrm{PiB}$ positive [139], reminiscent of ApoE4 effects on lower CSF A $\beta_{42}$. An association between ApoE4 and increased PiB PET retention was 
reported in cross-sectional [140] and longitudinal [141] analyses of $\mathrm{AD}$ cohorts, while some investigations found no such association [99, 138, 142], and ApoE2 was associated with lower PiB PET retention [136]. The reason for preserved cognition despite significant plaque load in $\mathrm{PiB}$ positive $\mathrm{NCI}$ is not clear. It has been suggested that resilience to $\mathrm{AD}$ pathology can be due to less advanced "maturation" of amyloid plaques, preservation of neurons and synapses, less accumulation of soluble tau in synapses, and less severe inflammatory responses [143]. Nevertheless, PiB positive individuals with $\mathrm{NCI}$ are at risk for developing cognitive decline when compared with PiB negative individuals with NCI matched by age and education [132, 144-146], and PiB positive in elderly people with NCI is a marker for preclinical AD [1]. Similarly, PiB positive subjects with MCI are more likely to convert to $\mathrm{AD}[108,109,146]$, and individuals with amnestic MCI are more likely to be $\mathrm{PiB}$ positive than those with nonamnestic MCI $[147,148]$. Thus, amyloid PET imaging is useful in identifying people that will develop $\mathrm{AD}$, or those with pathology unrelated to $\mathrm{AD}$.

One of the main drawbacks of PiB-PET imaging is the short radioactive half-life of carbon-11 ( $\sim 20 \mathrm{~min})$, which limits the distribution of [C-11] PiB to PET imaging centers with on-site cyclotrons. However, longer-lived fluorine-18 (F-18)-labeled amyloid PET tracers have been developed that are similarly effective in detecting fibrillar $A \beta$ pathology $[149,150]$. [F-18] flutemetamol is a 3'-fluoro analog of PiB (3'-F-PiB) with similar retention characteristics, although slightly greater retention in white matter [151]. In a phase I clinical study of subjects with $\mathrm{NCI}$ and mild $\mathrm{AD}$, the $\mathrm{AD}$ group had greater retention of [F-18]flutemetamol in the neocortex and striatum but not in the white matter, cerebellum, and pons [152]. A multicenter phase II trial of [F-18]flutemetamol in 15 older patients with NCI $(>55$ years), 10 young subjects with $\mathrm{NCI}$ ( $<55$ years), 20 patients with amnestic MCI, and 27 patients with early $\mathrm{AD}$ reported $93.1 \%$ sensitivity and $93.3 \%$ specificity [153]. As expected, regional retention levels of [F-18]flutemetamol and PiB correlated strongly in $\mathrm{MCI}$ and $\mathrm{AD}$ [153], supporting the notion that these 2 related tracers are comparable in detecting fibrillar $\mathrm{A} \beta$ deposits in vivo. A clinicopathological study in a large end-of-life population demonstrated high sensitivity and specificity of [F-18]flutametamol [154]. [F-18]florbetapir [(E)4-(2-(6-(2-(2-(2-[F-18]-fluoroethoxy)ethoxy)ethoxy)pyridin-3yl)vinyl)- $N$-methyl benzenamine; [F-18]AV-45; or amyvid] [155] has also proven to be effective in imaging $A \beta$ fibrillar pathology in vivo [156]. Those with $\mathrm{AD}$ displayed higher [F-18]florbetapir retention in cortical regions when compared with NCI, while white matter and cerebellar retention was not different between $\mathrm{AD}$ and $\mathrm{NCI}$ [157]. In a large multicenter trial, positive [F-18]florbetapir PET scans were seen in $28 \%$ of NCI (>55 years old), $47 \%$ of MCI, and $85 \%$ with $\mathrm{AD}$ [158]. [F-18]florbetapir PET was negative in subjects with NCI younger than 50 years of age, and correlated with neuritic plaques assessed postmortem in 29 terminally ill patients [159]. High sensitivity and specificity was reported for [F-18]florbetapir PET using global cortical standardized uptake value ratio to differentiate AD from NCI [160]. [F-18]florbetaben [(E)4-(2-(4-(2-(2-(2-[F-18]fluoroethoxy)ethoxy)ethoxy)phenyl)-vinyl)- $N$-methyl-benzenamine; [F-18]AV-1 or BAY-94-9172] has higher neocortical PET retention in AD compared with NCI or patients with FTD [161, 162]. Increased [F-18]florbetaben gray matter retention was reported in $\mathrm{AD}$ compared with $\mathrm{MCI}$ or nonAD dementias [163]. High sensitivity and specificity of [F-18]florbetaben was seen in a multicenter phase II study consisting of 69 subjects with NCI and 81 with clinically probable $\mathrm{AD}$ [164], a single-center phase 0 study of 10 subjects with $\mathrm{NCI}$ and 10 patients with clinically probable AD [165], and in a clinicopathological study from a multicenter phase III trial [166]. These studies indicate the utility of these new tracers as markers for $\mathrm{AD}$.

Non-amyloid PET imaging methods can provide complementary information, such as assessing neuronal dysfunction with FDG-PET [167]. In patients with AD, decreased FDGPET levels of cerebral glucose metabolism show a typical regional pattern of posterior temporoparietal to frontal hypometabolism [168-170]. Similar changes in cerebral metabolism were reported in NCI individuals with an ApoE4 allelle [171, 172], and in MCI [173-180]. FDG PET also predicted progression from NCI and MCI to AD [181-183]. The relationship between PiB-PET and FDG-PET remains to be determined in studies involving large cohorts of individuals with NCI, MCI, and AD. Agreement between these 2 methods is high in differentiating AD from NCI, but lower in classifying those with MCI [184]. MCI subjects were noticed to display positive correlations between PiB-PET and FDG-PET, possibly reflecting increased brain reserve in nonconverting MCI subjects [185]. Lowe et al. [147] reported that PiB-PET and FDG-PET had similar diagnostic accuracy, however, PiB PET was significantly better at separating MCI subtypes. In contrast, others have not observed significant correlations between PiB-PET and FDGPET in patients with $\mathrm{AD}$, and cognitive performance correlated strongly with FDG-PET but not with PiB-PET [186]. Amyloid deposition and brain atrophy are common in older individuals with NCI and MCI [100], and hippocampal atrophy can be detected in elderly NCI, MCI and AD using structural MRI [187-191]. MRI studies demonstrated that the rate of hippocampal atrophy is associated with conversion from MCI to AD [189, 192-197]. Globally, cerebral atrophy is observed spreading from within the MTL (i.e., hippocampal volume and entorhinal cortex thickness) to the parietal, occipital, and frontal lobes over the course of the disease, with future MCI converters most closely reflecting this pattern and exhibiting the highest rates of change [198-200]. Notably, a significant positive correlation was reported between rates of whole- 
brain atrophy on volumetric MRI and cortical PiB PET retention in AD [201-204].

$\mathrm{AD}$ is a multiproteinopathy with fibrillar aggregates of both $A \beta$ and tau. While $A \beta$ is widely believed to precede tau pathology, when compared with amyloid plaques NFTs correlate better with cognitive dysfunction in AD [205]. Thus, the recent development of tau-specific tracers has been an important advance to complement amyloid imaging, although less vigorously characterized and validated [206]. Multiple challenges associated with development of tau ligands relate to different ultrastructural and isoform composition of tau deposits, and have been addressed elsewhere [207]. Several groups reported tau-selective PET radioligands, including [F-18]-labeled THK compounds [208-217]; PBB compounds [218-220]; and [F-18]-labeled T807 and T808 compounds [18, 19, 221-224]; and with the tau imaging field developing rapidly new PET tracers are emerging [225]. Characterization studies of many of these tau candidate ligands are ongoing in subjects with $\mathrm{NCI}$ and $\mathrm{AD}$, while studies of $\mathrm{MCI}$ are just emerging. [F18]AV-1451 (or [F18]T807) has a promising pattern of retention corresponding to known distribution of NFT in AD brains [226]. This ligand shows an association with cognitive impairment [17, 227], greater PET retention in the oldest with NCI [19], MCI, and AD compared with younger subjects with NCI [221]. In elderly NCI from the Harvard Aging Brain Study Cohort, cortical [18-F]AV-1451 PET correlated with CSF measures of total tau and phosphorylated tau [228]. [18-F]AV-1451 PET was abnormally high in cortical, entorhinal, and parahippocampal regions (but not in the hippocampus) in individuals with $\mathrm{MCI}$ and $\mathrm{AD}$ compared with patients with $\mathrm{NCI}$ and greater radioligand retention in the inferior temporal gyrus correlated with impaired cognition $[18,19]$. Another study of [18-F]AV-1451 PET (20 patients with $\mathrm{NCI}, 15$ with $\mathrm{MCI}$, and 20 with $\mathrm{AD}$ ) observed that retention was increased in multiple cortical regions in patients with $\mathrm{AD}$ and in the entorhinal cortex in MCI; increased PET retention correlated with impaired global cognitive performance [229]. It has also been reported that regional [F-18]AV-1451 PET retention corresponded to clinical manifestation of $\mathrm{AD}$ and increased [F-18]AV-1451 PET signal in the hippocampus correlated strongly with regional structural MR (volume) impairment only in the presence of $A \beta$ pathology [230]. Although these reports indicate that [F-18]AV-1451 may be an additional tool for diagnosing $\mathrm{AD}$, a lack of extensive imaging-topostmortem validation impedes further advancement in the field [206]. Only a limited in number tau ligand autoradiographic investigations using autopsy tissue sections have compared AD with non-AD tauopathy cases. Two studies have reported that AV-1451 binds preferentially to $\mathrm{AD}$ tau isoforms and displays a binding distribution corresponding better to NFTs than to $A \beta$ plaques $[231,232]$. While binding to TDP-43 and $\alpha$-synuclein pathology was minimal or absent, these studies identified off-target binding in some areas, which requires further investigation [231, 232]. Another investigation of [F-18]AV-1451 binding using postmortem brain tissue also reported high specific signal in AD compared with nonAD tauopathies, however, no correlation was observed with tau pathology load within groups [233]. [F-18]AV-1451 imaging combined with postmortem histopathology of an autopsy case carrying the microtubule-associated protein tau (MAPT) gene mutation showed a strong correlation between regional tau pathology and antemortem PET retention [234]. The extent to which tau PET radioligands can discriminate between the accumulation of tau pathology in $\mathrm{AD}$ and other age-related tauopathies remains to be determined [235].

Although amyloid and tau PET imaging represent major advances in $\mathrm{AD}$, there are still a number of limitations and unresolved questions. In contrast to their good specificity, the sensitivity of PiB-PET imaging and related [F-18] ligands is not well characterized for relatively low but histologically detectable $A \beta$ deposits. Analyses of large numbers of PETpositive and PET-negative cases, with short imaging-toautopsy interval, will be required to establish threshold levels of $A \beta$ and tau pathologies necessary for diagnostic accuracy. A major challenge for neuroimaging in $\mathrm{AD}$ is how to determine the onset of amyloid and tau accumulation in pathologyburdened individuals with $\mathrm{NCI}$ and $\mathrm{MCI}$, and its association with cognitive measures and CSF biomarkers. As the field focuses on PET imaging studies to help determine the clinical significance of presymptomatic pathology and identify people at risk for cognitive decline, more studies are needed to compare directly the relative merit of amyloid and tau PET to CSF biomarkers, MRI, FDG, and clinical measures for earlier detection of $\mathrm{AD}$, to improve the selection of patients for clinical trials, and for monitoring pathology progression and therapeutic efficacy.

\section{Blood-Based biomarkers}

The resources and costs related to CSF and imaging biomarkers make it difficult to incorporate them into routine clinical practice. Thus, there is a focus on the discovery and validation of biomarkers in peripheral blood. As blood collection is minimally invasive and inexpensive to perform, bloodbased biomarkers, developed and refined based on strong concordance with CSF and brain imaging parameters, would present a significant breakthrough in moving routine screening for incipient dementia into community-based clinics. However, the seclusion of the central nervous system (CNS) from the peripheral circulatory system is a significant challenge for blood-based biomarkers to diagnose neurological disorders such as AD. Nevertheless, discovery- and hypothesis-based approaches have led to the identification of numerous biomarker candidates associated with $\mathrm{AD}$ in blood, plasma, and serum. 
To date, plasma $A \beta$ and tau levels have not mirrored the sensitivity and specificity of their CSF counterparts. In general, $A \beta_{42}$ or $A \beta_{40}$ levels in plasma are found to be either unchanged or, in cases where higher plasma levels of either $A \beta_{42}$ or $A \beta_{40}$ are reported for $A D$, there is broad overlap between patients and controls [236]. With respect to predicting $\mathrm{AD}$ conversion in cognitively normal people, some studies report that high plasma $A \beta_{42}$, or a high $A \beta_{42} / A \beta_{40}$ ratio, is a risk indicator for future $A D$, whereas others report the opposite [237-239]. These equivocal findings suggest that plasma $A \beta$ does not reflect brain $A \beta$ turnover or metabolism [28]. For instance, there is no correlation between plasma $A \beta$ species and brain amyloid load as determined by PiB binding [104]. Plasma assays for tau have been hampered by a lack of analytical sensitivity for accurate measurement. However, the recent application of digital ELISA technology revealed that plasma tau levels were significantly higher in patients with $\mathrm{AD}$ compared with controls and those with MCI, but with substantial overlap among the groups, with no correlation between tau levels in plasma and CSF [240]. In a significant advance for examining amyloid and tau in blood, Fiandaca et al. [241] examined these proteins in neurally derived blood exosomes derived from patients with $\mathrm{AD}$, with FTD, and healthy controls [241]. Blood exosomal levels of total tau, phospho-tau (T181), phospho-tau (S396), and $\mathrm{A} \beta_{42}$ were significantly higher in patients with $\mathrm{AD}$ than in matched controls, with combined levels showing 96\% sensitivity. Moreover, analysis of blood exosomes in a group of $\mathrm{AD}$ patients at two different time points showed that the levels of these four markers were elevated in the blood of cognitively normal individuals who later developed $\mathrm{AD}$, up to 10 years before clinical diagnosis of the disease [241]. Hence exosomes may provide a blood-based window into CNS activity and provide a more suitable substrate for marking preclinical $\mathrm{AD}$ stages.

Several studies have reported promising novel blood biomarkers for AD. Combined multivariate analysis of levels of 120 known signaling and inflammatory proteins in plasma identified 18 candidate proteins that together identified patients with $\mathrm{AD}$ and predicted future $\mathrm{AD}$ in those with $\mathrm{MCI}$ with high accuracy [242]. Another study using plasma from patients with probable $\mathrm{AD}$ and controls found a significant $\mathrm{AD}$-related increase in the ratio of proatrial natriuretic peptide, a vasodilator, to carboxy-terminal endothelin-1 precursor fragment, a vasoconstrictor (training set sensitivity $=81 \%$, specificity $=82 \%$ ) [243]. O'Bryant et al. [244] performed multianalyte profiling of 396 control and AD serum samples from the Texas Alzheimer's Research Consortium and 170 control and AD plasma samples from ADNI to develop a novel serum plasma biomarker algorithm based on 11 proteins differentially expressed between the two diagnostic groups (e.g., C-reactive protein, adiponectin, and pancreatic polypeptide). When combined with biological (e.g., glucose, cholesterol) and demographic (e.g., age, apoE status) variables, the biomarker yielded good accuracy $(\mathrm{AUC}=0.88)$ comparable with the CSF total $\operatorname{tau} / \mathrm{A} \beta_{42}(\mathrm{AUC}=0.92)$ for these patients [244].

More recently, Doecke et al. [245] identified a plasma biomarker panel that consisted of 18 proteins, including cortisol, ApoE, pancreatic polypeptide, and epidermal growth factor receptor, that discriminated patients with $\mathrm{AD}$ from healthy controls, with high sensitivity and specificity $(85 \%$ and $93 \%$, respectively). $\mathrm{Hu}$ et al. [246] identified 17 proteins and peptides that were associated with $\mathrm{MCI}$ or $\mathrm{AD}$ in a test cohort, which yielded four candidates in the validation cohort. Two of these four analytes, pancreatic polypeptide and ApoE, were among those included in the plasma biomarker panel developed by Doecke et al. [245]. However, Hu et al. [246] found that a different set of two plasma proteins, pancreatic polypeptide and B-type natriuretic peptide, were correlated with CSF levels of $A \beta_{42}$ and total tau/ $\mathrm{A} \beta_{42}$ ratios. This concordance with core CSF biomarkers suggested that these two peptides could be useful blood surrogates for predicting the progression to clinical $\mathrm{AD}$.

A newly developed SOMAscan discovery-based platform was used to analyze 1129 plasma proteins simultaneously in blood samples from patients with $\mathrm{AD}$ and healthy controls [247]. In the discovery set, a 5-protein classifier (S100A9, CD84, CD226, AIF1, and ESAM) was identified that discriminated people with $\mathrm{AD}$ from healthy controls with a sensitivity and specificity of $90.0 \%$ and $84.2 \%$, respectively, outperforming CSF tau and $\mathrm{A} \beta_{42}$ markers from the same cases. In a validation study, the classifier discriminated controls from individuals with MCI with $96.7 \%$ sensitivity and $80 \%$ specificity [247]. Finally, an unbiased mass spectrometric lipidomics approach was used to identify a plasma phospholipid panel that predicted phenoconversion to $\mathrm{MCI}$ or $\mathrm{AD}$ within a 2 to 3-year timeframe with $>90 \%$ accuracy [248]. Thus, these novel discovery-based studies in plasma may also prove useful in the detection of $\mathrm{AD}$ in its earliest stages.

The field of blood-based biomarkers lags behind that of CSF as there is a significant lack of standardization in collection procedures and analytical platforms, which likely provides the main source for variability and low reproducibility rates across centers [241, 247, 249]. In this regard, an initial set of guidelines was developed to standardize the preanalytical procedures related to the utilization of blood-based biomarkers [250]. Once refined, a set of universal guidelines will allow the field to more accurately assess and cross-validate potential blood-based biomarkers to home in on a panel that either augments existing core CSF and imaging parameters or provides suitable diagnostic accuracy for noninvasive, low-cost screening for incipient dementia in community settings.

\section{Circulating Autoantibodies as Biomarkers}

Blood-based autoantibodies against neuronal proteins associated with neuroinflammation, vascular dysfunction/blood-brain barrier 
(BBB) disruption, and altered cholesterol/lipid metabolism suggest that autoimmunity markers may correlate with specific stages in the pathophysiology and comorbidities associated with AD.

The initial indication that autoimmunity could play role in the pathophysiology of $\mathrm{AD}$ was based on the identification of $A \beta$ autoantibodies in cognitively normal older individuals [251-253]. Based on these results, active and passive amyloid immunotherapy has been tested in patients with AD [254-256]. Although active immunotherapy did not prove to be an effective treatment for patients with $\mathrm{AD}$, administration of anti-A $\beta$ antibodies is still currently being tested in patients with $\mathrm{AD}$ as therapeutic agents (i.e., aducanumab) [257-259]. The results released from the phase $\mathrm{Ib}$ trial for aducanumab indicate an encouraging reduction in brain amyloid and slowing of cognitive decline in patients with CDRs of 0.5 and 1.0 [259]. Nevertheless, while the scientific community anxiously awaits the results of passive $A \beta$ immunotherapy in phase III trials, other autoantibodies have been identified as potential diagnostic biomarkers for AD [260, 261].

The use of protein, peptides, and even peptoid arrays has led to the identification of autoantibodies specific to patients with AD. Autoantibodies against targets involved in synaptic activity, including neurotransmitters and receptors, are associated with cognitive decline, suggesting their use as signals of brain malfunction [262-271] (Table 1). With respect to inflammation, the relationship between neurodegeneration and autoimmunity was recently genetically confirmed in an epidemiological study where specific single-nucleotide polymorphisms in TREM2 (triggering receptor expressed on myeloid cells 2) and complement factors were shown to overlap between $\mathrm{AD}$ and immune diseases [272]. These findings suggest that alterations of the BBB and activation of neuroinflammation are intrinsic components of $\mathrm{AD}$ pathophysiology. In this regard, autoantibodies against glial fibrillary acidic protein and $\mathrm{S} 100 \beta$ have been associated with leakiness of the BBB and peripheral immune cell access to the CNS [263, 273]. Autoantibodies against other proteins that modulate the
Table 1 Autoantibodies found associated with Alzheimer's disease

\begin{tabular}{|c|c|c|}
\hline Biological function & Target protein & References \\
\hline \multirow[t]{9}{*}{ Synaptic transmission } & Dopamine & {$[262,263]$} \\
\hline & Serotonin & {$[262,263]$} \\
\hline & Glutamate & {$[262,263]$} \\
\hline & Hydroxytryptamine & {$[262,263]$} \\
\hline & Adrenergic receptors & {$[264,265]$} \\
\hline & $\mathrm{N}$-methyl-D-aspartate glutamate receptors & {$[266-268]$} \\
\hline & Nicotinic acetycholine receptor & [269] \\
\hline & Amphiphysin-1 & {$[270]$} \\
\hline & Proopiomelanocortin & [271] \\
\hline \multirow[t]{4}{*}{ Inflammation } & Glial fibrillary acidic protein & {$[263,273]$} \\
\hline & $\mathrm{S} 100 \beta$ & {$[263,273]$} \\
\hline & Galectin 1 & [271] \\
\hline & MAPKAPK5 & [271] \\
\hline \multirow[t]{2}{*}{ Blood-brain barrier/endothelial } & Rabaptin 5 & [274] \\
\hline & Angiotensin-2 type-1 receptor & [275] \\
\hline \multirow[t]{7}{*}{ Metabolism } & Oxidized low-density lipoproteins & [278] \\
\hline & Phosphorylcholine & {$[277,279,280]$} \\
\hline & Gangliosides GM1 And GQ1b & {$[276,281]$} \\
\hline & Aldolase & {$[282-284]$} \\
\hline & ATP synthase $\beta$ & {$[282-284]$} \\
\hline & Mitochondrial ribosomal protein L34 & {$[271]$} \\
\hline & Pentatricopeptide repeat domain 2 & {$[271]$} \\
\hline \multirow[t]{5}{*}{ Gene expression } & FERM domain containing 8 & {$[271]$} \\
\hline & C9orf9 & {$[271]$} \\
\hline & Centaurin, alpha 2 & {$[271]$} \\
\hline & DnaJ homolog subfamily C & {$[271]$} \\
\hline & Ankyrin repeat and $\mathrm{KH}$ domain containing 1 & {$[271]$} \\
\hline
\end{tabular}

MAPKAPK5 = mitogen-activated protein kinase-activated protein kinase 5; ATP $=$ adenosine triphosphate 
BBB have also been identified (Table 1) [274, 275]. Detection of autoantibodies is also associated with metabolic dysfunction and oxidative stress [276-281] (Table 1). Autoantibodies against proteins involved in energy metabolism, such as aldolase and adenosine triphosphate synthase $\beta$, have also been shown to be significantly higher in the sera of patients with $\mathrm{AD}$ than in healthy individuals [282-284]. The role of the antigenic proteins and the role of autoimmunity in the pathophysiology of $\mathrm{AD}$ is still unclear, but there is enough evidence to suggest that further studies could lead to the establishment of an autoimmune panel with increased specificity and sensitivity for differentiating among $\mathrm{AD}$, normal aging, and other dementing disease processes.

\section{Blood Metabolites}

Lipids, amino acids, vitamins, and cholesterol are plasma metabolites that have been associated with AD [285]. Higher levels of cholesterol are associated with increased metabolism of amyloid precursor protein [286]. Consistently, a high cholesterol level in serum is associated with higher risk of cognitive impairment and AD. By contrast, reduced levels of plasma antioxidants, such as vitamin E, C, D, and others, correlated with both vascular dementia and AD [287, 288]. Recently, a panel of 24 plasma metabolites was developed as diagnostic biomarkers of $\mathrm{AD}$ that included phosphocholine metabolites and amino acids [289]. The differential abundance of the 24 metabolites accounted for a $90 \%$ sensitivity as biomarkers for the preclinical stage of AD. The authors anticipate challenges associated with validation and reproduction of the results obtained in different cohorts [289]. Differential comorbidities, especially metabolic disorders such as diabetes and hyperlipidemia, may also contribute to the lack of specificity and sensitivity desired for the use of metabolic biomarkers as a diagnostic tool. Moreover, current instrumentation and analytical software limitations preclude the analysis of the whole metabolome. Despite these technical obstacles, the combination of identified metabolites and autoantibodies could be a robust analytical panel for the preclinical diagnosis of AD.

\section{Conclusion}

Several potential disease-modifying drugs have been developed for $\mathrm{AD}$ based on translational rationales, yet have failed to show any effect on disease progression or cognitive function in clinical trials. However, these failures may simply be due to the fact that the patients with $\mathrm{AD}$ being treated are already too advanced to derive a clinical benefit. Thus, well-validated biomarkers for early detection and accurate diagnosis of the preclinical stages of $\mathrm{AD}$ will be crucial for therapeutic advancement. While positive amyloid or tau tracer retention on PET imaging, low CSF concentrations of $A \beta_{42}$, and high CSF concentrations in total tau and phospho-tau are accurate biomarkers for the progression to $\mathrm{AD}$, the ultimate $\mathrm{AD}$ biomarker panel will likely show improved reliability for detecting preclinical $\mathrm{AD}$ through the inclusion of novel markers that are more precisely associated with confirmed pathophysiologic mechanisms. In this regard, it is imperative to recognize $\mathrm{AD}$ as a multifactorial disease arising from heterogeneous etiologies, and that a combinatorial approach of imaging and fluid biomarkers reflecting disease pathogenesis integrated with genetic screening and sensitive neuropsychological testing will be required. In addition, the establishment of standards for sample collection and the unified calibration of specific instrumentation will be necessary to avoid multicenter variability. Altogether, the results described here illustrate that the field is inching closer to the development of a reliable and accurate diagnostic tool that will lead to the discovery of efficient therapeutic strategies for combating the onset of dementia.

Acknowledgments This study was supported by National Institutes of Health grants PO1AG14449, RO1AG043375, AG025204, AG052528, R21AG026032, and R21AG042146; the Saint Mary's Foundation, Miles for Memories of Battle Creek, MI; and Barrow Neurological Institute Barrow and Beyond.

\section{References}

1. Sperling RA, Aisen PS, Beckett LA, et al. Toward defining the preclinical stages of Alzheimer's disease: recommendations from the National Institute on Aging-Alzheimer's Association workgroups on diagnostic guidelines for Alzheimer's disease. Alzheimers Dement 2011;7:280-292.

2. Sperling RA, Karlawish J, Johnson KA. Preclinical Alzheimer disease-the challenges ahead. Nat Rev Neurol 2013;9:54-58.

3. Morris JC, Storandt M, Miller JP, et al. Mild cognitive impairment represents early-stage Alzheimer disease. Arch Neurol 2001;58: 397-405.

4. Price JL, Morris JC. Tangles and plaques in nondemented aging and "preclinical" Alzheimer's disease. Ann Neurol 1999;45:358368.

5. Bennett DA, Schneider JA, Bienias JL, Evans DA, Wilson RS. Mild cognitive impairment is related to Alzheimer disease pathology and cerebral infarctions. Neurology 2005;64:834-841.

6. Markesbery WR, Schmitt FA, Kryscio RJ, Davis DG, Smith CD, Wekstein DR. Neuropathologic substrate of mild cognitive impairment. Arch Neurol 2006;63:38-46.

7. Mufson EJ, Chen EY, Cochran EJ, Beckett LA, Bennett DA, Kordower JH. Entorhinal cortex beta-amyloid load in individuals with mild cognitive impairment. Exp Neurol 1999;158:469-490.

8. Weiner MW, Veitch DP, Aisen PS, et al. 2014 Update of the Alzheimer's Disease Neuroimaging Initiative: A review of papers published since its inception. Alzheimers Dement 2015;11:e1-120.

9. Jack CR, Jr., Knopman DS, Jagust WJ, et al. Hypothetical model of dynamic biomarkers of the Alzheimer's pathological cascade. Lancet Neurol 2010;9:119-128. 
10. Fagan AM, Roe CM, Xiong C, Mintun MA, Morris JC, Holtzman DM. Cerebrospinal fluid tau/beta-amyloid(42) ratio as a prediction of cognitive decline in nondemented older adults. Arch Neurol 2007;64:343-349.

11. Mattsson N, Zetterberg H, Hansson O, et al. CSF biomarkers and incipient Alzheimer disease in patients with mild cognitive impairment. JAMA 2009;302:385-393.

12. Snider BJ, Fagan AM, Roe C, et al. Cerebrospinal fluid biomarkers and rate of cognitive decline in very mild dementia of the Alzheimer type. Arch Neurol 2009;66:638-645.

13. Trojanowski JQ, Vandeerstichele H, Korecka M, et al. Update on the biomarker core of the Alzheimer's Disease Neuroimaging Initiative subjects. Alzheimers Dement 2010;6:230-238.

14. Mattsson N, Tosun D, Insel PS, et al. Association of brain amyloid-beta with cerebral perfusion and structure in Alzheimer's disease and mild cognitive impairment. Brain 2014;137:1550-1561.

15. Tosun D, Joshi S, Weiner MW, the Alzheimer's Disease Neuroimaging I. Multimodal MRI-based imputation of the Abeta+ in early mild cognitive impairment. Ann Clin Transl Neurol 2014;1:160-170.

16. Bangen KJ, Restom K, Liu TT, et al. Assessment of Alzheimer's disease risk with functional magnetic resonance imaging: an arterial spin labeling study. J Alzheimers Dis 2012;31(Suppl. 3):S59S74.

17. Brier MR, Gordon B, Friedrichsen K, et al. Tau and Abeta imaging, CSF measures, and cognition in Alzheimer's disease. Sci Transl Med 2016;8:338ra66.

18. Johnson KA, Schultz A, Betensky RA, et al. Tau positron emission tomographic imaging in aging and early Alzheimer disease. Ann Neurol 2016;79:110-119.

19. Scholl M, Lockhart SN, Schonhaut DR, et al. PET imaging of tau deposition in the aging human brain. Neuron 2016;89:971-982.

20. Seubert P, Vigo-Pelfrey C, Esch F, et al. Isolation and quantification of soluble Alzheimer's beta-peptide from biological fluids. Nature 1992;359:325-327.

21. Farlow M, Ghetti B, Benson MD, Farrow JS, van Nostrand WE, Wagner SL. Low cerebrospinal-fluid concentrations of soluble amyloid beta-protein precursor in hereditary Alzheimer's disease. Lancet 1992;340:453-454.

22. Van Nostrand WE, Wagner SL, Shankle WR, et al. Decreased levels of soluble amyloid beta-protein precursor in cerebrospinal fluid of live Alzheimer disease patients. Proc Natl Acad Sci U S A 1992;89:2551-2555.

23. van Gool WA, Kuiper MA, Walstra GJ, Wolters EC, Bolhuis PA. Concentrations of amyloid beta protein in cerebrospinal fluid of patients with Alzheimer's disease. Ann Neurol 1995;37:277-279.

24. Iwatsubo T, Odaka A, Suzuki N, Mizusawa H, Nukina N, Ihara Y. Visualization of A beta 42(43) and A beta 40 in senile plaques with end-specific A beta monoclonals: evidence that an initially deposited species is A beta 42(43). Neuron 1994;13:45-53.

25. Jarrett JT, Berger EP, Lansbury PT, Jr. The carboxy terminus of the beta amyloid protein is critical for the seeding of amyloid formation: implications for the pathogenesis of Alzheimer's disease. Biochemistry 1993;32:4693-4697.

26. Andreasen N, Blennow K. Beta-amyloid (Abeta) protein in cerebrospinal fluid as a biomarker for Alzheimer's disease. Peptides 2002;23:1205-1214.

27. Andreasen N, Hesse C, Davidsson P, et al. Cerebrospinal fluid beta-amyloid(1-42) in Alzheimer disease: differences between early- and late-onset Alzheimer disease and stability during the course of disease. Arch Neurol 1999;56:673-680.

28. Mehta PD, Pirttila T, Mehta SP, Sersen EA, Aisen PS, Wisniewski HM. Plasma and cerebrospinal fluid levels of amyloid beta proteins 1-40 and 1-42 in Alzheimer disease. Arch Neurol 2000;57: 100-105.
29. Sunderland T, Linker G, Mirza N, et al. Decreased beta-amyloid142 and increased tau levels in cerebrospinal fluid of patients with Alzheimer disease. JAMA 2003;289:2094-2103.

30. Vandermeeren M, Mercken M, Vanmechelen E, et al. Detection of tau proteins in normal and Alzheimer's disease cerebrospinal fluid with a sensitive sandwich enzyme-linked immunosorbent assay. $\mathrm{J}$ Neurochem 1993;61:1828-1834.

31. Blennow K, Wallin A, Agren H, Spenger C, Siegfried J, Vanmechelen E. Tau protein in cerebrospinal fluid: a biochemical marker for axonal degeneration in Alzheimer disease? Mol Chem Neuropathol 1995;26:231-245.

32. Mori H, Hosoda K, Matsubara E, et al. Tau in cerebrospinal fluids: establishment of the sandwich ELISA with antibody specific to the repeat sequence in tau. Neurosci Lett 1995;186:181-183.

33. Vigo-Pelfrey C, Seubert P, Barbour R, et al. Elevation of microtubule-associated protein tau in the cerebrospinal fluid of patients with Alzheimer's disease. Neurology 1995;45:788-793.

34. Hu YY, He SS, Wang X, et al. Levels of nonphosphorylated and phosphorylated tau in cerebrospinal fluid of Alzheimer's disease patients : an ultrasensitive bienzyme-substrate-recycle enzymelinked immunosorbent assay. Am J Pathol 2002;160:1269-1278.

35. Kohnken R, Buerger K, Zinkowski R, et al. Detection of tau phosphorylated at threonine 231 in cerebrospinal fluid of Alzheimer's disease patients. Neurosci Lett 2000;287:187-190.

36. Vanmechelen E, Vanderstichele H, Davidsson P, et al. Quantification of tau phosphorylated at threonine 181 in human cerebrospinal fluid: a sandwich ELISA with a synthetic phosphopeptide for standardization. Neurosci Lett 2000;285:49-52.

37. Blennow K. Cerebrospinal fluid protein biomarkers for Alzheimer's disease. NeuroRx 2004;1:213-225.

38. Maddalena A, Papassotiropoulos A, Muller-Tillmanns B, et al. Biochemical diagnosis of Alzheimer disease by measuring the cerebrospinal fluid ratio of phosphorylated tau protein to betaamyloid peptide42. Arch Neurol 2003;60:1202-1206.

39. Kapaki E, Paraskevas GP, Zalonis I, Zournas C. CSF tau protein and beta-amyloid (1-42) in Alzheimer's disease diagnosis: discrimination from normal ageing and other dementias in the Greek population. Eur J Neurol 2003;10:119-128.

40. Babic M, Svob Strac D, Muck-Seler D, et al. Update on the core and developing cerebrospinal fluid biomarkers for Alzheimer disease. Croat Med J 2014;55:347-365.

41. Blennow K, Dubois B, Fagan AM, Lewczuk P, de Leon MJ, Hampel H. Clinical utility of cerebrospinal fluid biomarkers in the diagnosis of early Alzheimer's disease. Alzheimers Dement 2015;11:58-69.

42. Kang JH, Korecka M, Toledo JB, Trojanowski JQ, Shaw LM. Clinical utility and analytical challenges in measurement of cerebrospinal fluid amyloid-beta(1-42) and tau proteins as Alzheimer disease biomarkers. Clin Chem 2013;59:903-916.

43. Riemenschneider M, Lautenschlager N, Wagenpfeil S, Diehl J, Drzezga A, Kurz A. Cerebrospinal fluid tau and beta-amyloid 42 proteins identify Alzheimer disease in subjects with mild cognitive impairment. Arch Neurol 2002;59:1729-1734.

44. Buerger K, Ewers M, Andreasen N, et al. Phosphorylated tau predicts rate of cognitive decline in MCI subjects: a comparative CSF study. Neurology 2005;65:1502-1503.

45. Buerger K, Teipel SJ, Zinkowski R, et al. CSF tau protein phosphorylated at threonine 231 correlates with cognitive decline in MCI subjects. Neurology 2002;59:627-629.

46. Hansson O, Zetterberg H, Buchhave P, Londos E, Blennow K, Minthon L. Association between CSF biomarkers and incipient Alzheimer's disease in patients with mild cognitive impairment: a follow-up study. Lancet Neurol 2006;5:228-234.

47. Duits FH, Teunissen CE, Bouwman FH, et al. The cerebrospinal fluid "Alzheimer profile": easily said, but what does it mean? Alzheimers Dement 2014;10:713-23 e2. 
48. Petersen RC, Smith GE, Ivnik RJ, et al. Apolipoprotein E status as a predictor of the development of Alzheimer's disease in memoryimpaired individuals. JAMA 1995;273:1274-1278.

49. Engelborghs S, Sleegers K, Cras P, et al. No association of CSF biomarkers with APOEepsilon4, plaque and tangle burden in definite Alzheimer's disease. Brain 2007;130:2320-2326.

50. Lautner R, Palmqvist S, Mattsson N, et al. Apolipoprotein E genotype and the diagnostic accuracy of cerebrospinal fluid biomarkers for Alzheimer disease. JAMA Psychiatry 2014;71:11831191.

51. Leoni V. The effect of apolipoprotein E (ApoE) genotype on biomarkers of amyloidogenesis, tau pathology and neurodegeneration in Alzheimer's disease. Clin Chem Lab Med 2011;49:375383.

52. Sutphen CL, Jasielec MS, Shah AR, et al. Longitudinal cerebrospinal fluid biomarker changes in preclinical Alzheimer disease during middle age. JAMA Neurol 2015;72:1029-1042.

53. Toledo JB, Zetterberg H, van Harten AC, et al. Alzheimer's disease cerebrospinal fluid biomarker in cognitively normal subjects. Brain 2015;138:2701-2715.

54. Verwey NA, van der Flier WM, Blennow K, et al. A worldwide multicentre comparison of assays for cerebrospinal fluid biomarkers in Alzheimer's disease. Ann Clin Biochem 2009;46: 235-240.

55. Shaw LM, Vanderstichele H, Knapik-Czajka M, et al. Cerebrospinal fluid biomarker signature in Alzheimer's disease neuroimaging initiative subjects. Ann Neurol 2009;65:403-413.

56. Shaw LM, Vanderstichele H, Knapik-Czajka M, et al. Qualification of the analytical and clinical performance of CSF biomarker analyses in ADNI. Acta Neuropathol 2011;121:597609.

57. Toledo JB, Xie SX, Trojanowski JQ, Shaw LM. Longitudinal change in CSF Tau and Abeta biomarkers for up to 48 months in ADNI. Acta Neuropathol 2013;126:659-670.

58. Buchhave P, Minthon L, Zetterberg H, Wallin AK, Blennow K, Hansson O. Cerebrospinal fluid levels of beta-amyloid 1-42, but not of tau, are fully changed already 5 to 10 years before the onset of Alzheimer dementia. Arch Gen Psychiatry 2012;69:98-106.

59. Pettigrew C, Soldan A, Moghekar A, et al. Relationship between cerebrospinal fluid biomarkers of Alzheimer's disease and cognition in cognitively normal older adults. Neuropsychologia 2015;78:63-72.

60. Counts SE, Mufson EJ. Putative CSF protein biomarker candidates for amnestic mild cognitive impairment. Transl Neurosci 2010;1:2-8

61. Perrin RJ, Craig-Schapiro R, Malone JP, et al. Identification and validation of novel cerebrospinal fluid biomarkers for staging early Alzheimer's disease. PLOS ONE 2011;6:e16032.

62. Roe CM, Fagan AM, Williams MM, et al. Improving CSF biomarker accuracy in predicting prevalent and incident Alzheimer disease. Neurology 2011;76:501-510.

63. Puchades M, Hansson SF, Nilsson CL, Andreasen N, Blennow K, Davidsson P. Proteomic studies of potential cerebrospinal fluid protein markers for Alzheimer's disease. Brain Res Mol Brain Res 2003;118:140-146.

64. Zhang J, Sokal I, Peskind ER, et al. CSF multianalyte profile distinguishes Alzheimer and Parkinson diseases. Am J Clin Pathol 2008;129:526-529.

65. Li G, Peskind ER, Millard SP, et al. Cerebrospinal fluid concentration of brain-derived neurotrophic factor and cognitive function in non-demented subjects. PLOS ONE 2009;4:e5424.

66. Lovell MA, Lynn BC, Xiong S, Quinn JF, Kaye J, Markesbery WR. An aberrant protein complex in CSF as a biomarker of Alzheimer disease. Neurology 2008;70:2212-2218.

67. Mukaetova-Ladinska EB, Milne J, Andras A, et al. Alpha- and gamma-synuclein proteins are present in cerebrospinal fluid and are increased in aged subjects with neurodegenerative and vascular changes. Dement Geriatr Cogn Disord 2008;26:32-42.

68. Toledo JB, Korff A, Shaw LM, Trojanowski JQ, Zhang J. CSF alpha-synuclein improves diagnostic and prognostic performance of CSF tau and Abeta in Alzheimer's disease. Acta Neuropathol 2013;126:683-697.

69. Iqbal K, Flory M, Khatoon S, et al. Subgroups of Alzheimer's disease based on cerebrospinal fluid molecular markers. Ann Neurol 2005;58:748-757.

70. Iqbal K, Grundke-Iqbal I. Elevated levels of tau and ubiquitin in brain and cerebrospinal fluid in Alzheimer's disease. Int Psychogeriatr 1997;9(Suppl. 1):289-296.

71. Brinkmalm A, Brinkmalm G, Honer WG, et al. SNAP-25 is a promising novel cerebrospinal fluid biomarker for synapse degeneration in Alzheimer's disease. Mol Neurodegener 2014;9:53.

72. Kvartsberg H, Duits FH, Ingelsson M, et al. Cerebrospinal fluid levels of the synaptic protein neurogranin correlates with cognitive decline in prodromal Alzheimer's disease. Alzheimers Dement 2015;11:1180-1190.

73. Tarawneh R, D'Angelo G, Crimmins D, et al. Diagnostic and prognostic utility of the synaptic marker neurogranin in Alzheimer disease. JAMA Neurol 2016;73:561-571.

74. Portelius E, Zetterberg H, Skillback T, et al. Cerebrospinal fluid neurogranin: relation to cognition and neurodegeneration in Alzheimer's disease. Brain 2015;138:3373-3385.

75. Kester MI, Teunissen CE, Sutphen C, et al. Cerebrospinal fluid VILIP-1 and YKL-40, candidate biomarkers to diagnose, predict and monitor Alzheimer's disease in a memory clinic cohort. Alzheimers Res Ther 2015;7:59.

76. Tarawneh R, Lee JM, Ladenson JH, Morris JC, Holtzman DM. CSF VILIP-1 predicts rates of cognitive decline in early Alzheimer disease. Neurology 2012;78:709-719.

77. Skillback T, Farahmand B, Bartlett JW, et al. CSF neurofilament light differs in neurodegenerative diseases and predicts severity and survival. Neurology 2014;83:1945-1953.

78. Skillback T, Zetterberg H, Blennow K, Mattsson N. Cerebrospinal fluid biomarkers for Alzheimer disease and subcortical axonal damage in 5,542 clinical samples. Alzheimers Res Ther 2013;5: 47.

79. Zetterberg H, Skillback T, Mattsson N, et al. Association of Cerebrospinal Fluid Neurofilament Light Concentration With Alzheimer Disease Progression. JAMA Neurol 2016;73:60-67.

80. Tarawneh R, D'Angelo G, Macy E, et al. Visinin-like protein-1: diagnostic and prognostic biomarker in Alzheimer disease. Ann Neurol 2011;70:274-285.

81. Counts SE, Mufson EJ. The role of nerve growth factor receptors in cholinergic basal forebrain degeneration in prodromal Alzheimer disease. J Neuropathol Exp Neurol 2005;64:263-272.

82. Fahnestock M, Michalski B, Xu B, Coughlin MD. The precursor pro-nerve growth factor is the predominant form of nerve growth factor in brain and is increased in Alzheimer's disease. Mol Cell Neurosci 2001;18:210-220.

83. Peng S, Wuu J, Mufson EJ, Fahnestock M. Increased proNGF levels in subjects with mild cognitive impairment and mild Alzheimer's disease. J Neuropathol Exp Neurol 2004;63:641-649.

84. Counts SE, He B, Prout JG, et al. Cerebrospinal fluid proNGF: a putative biomarker for early Alzheimer's disease. Curr Alzheimer Res 2016;13:800-808

85. Craig-Schapiro R, Perrin RJ, Roe CM, et al. YKL-40: a novel prognostic fluid biomarker for preclinical Alzheimer's disease. Biol Psychiatry 2010;68:903-912.

86. Armstrong A, Mattsson N, Appelqvist H, et al. Lysosomal network proteins as potential novel CSF biomarkers for Alzheimer's disease. Neuromolecular Med 2014;16:150-160.

87. Ginsberg SD, Alldred MJ, Counts SE, et al. Microarray analysis of hippocampal CA1 neurons implicates early endosomal 
dysfunction during Alzheimer's disease progression. Biol Psychiatry 2010;68:885-893.

88. Nixon RA. The role of autophagy in neurodegenerative disease. Nat Med 2013;19:983-997.

89. Tiernan CT, Ginsberg SD, Guillozet-Bongaarts AL, et al. Protein homeostasis gene dysregulation in pretangle bearing nucleus basalis neurons during the progression of Alzheimer's disease. Neurobiol Aging 2016;42:80-90.

90. Di Domenico F, Pupo G, Giraldo E, et al. Oxidative signature of cerebrospinal fluid from mild cognitive impairment and Alzheimer disease patients. Free Radic Biol Med 2016;91:1-9.

91. Montine TJ, Beal MF, Cudkowicz ME, et al. Increased CSF F2isoprostane concentration in probable AD. Neurology 1999;52: 562-565.

92. Pratico D, Clark CM, Liun F, Rokach J, Lee VY, Trojanowski JQ. Increase of brain oxidative stress in mild cognitive impairment: a possible predictor of Alzheimer disease. Arch Neurol 2002;59: 972-976.

93. Denk J, Boelmans K, Siegismund C, Lassner D, Arlt S, Jahn H. MicroRNA profiling of CSF reveals potential biomarkers to detect Alzheimer's disease. PLOS ONE 2015;10:e126423.

94. Liu CG, Wang JL, Li L, Wang PC. MicroRNA-384 regulates both amyloid precursor protein and beta-secretase expression and is a potential biomarker for Alzheimer's disease. Int J Mol Med 2014;34:160-166.

95. Sala Frigerio C, Lau P, Salta E, et al. Reduced expression of hsamiR-27a-3p in CSF of patients with Alzheimer disease. Neurology 2013;81:2103-2106.

96. Ferreira D, Perestelo-Perez L, Westman E, Wahlund LO, Sarria A, Serrano-Aguilar P. Meta-review of CSF core biomarkers in Alzheimer's disease: the state-of-the-art after the new revised diagnostic criteria. Front Aging Neurosci 2014;6:47.

97. Olsson B, Lautner R, Andreasson U, et al. CSF and blood biomarkers for the diagnosis of Alzheimer's disease: a systematic review and meta-analysis. Lancet Neurol 2016;15:673-684.

98. Palmqvist S, Zetterberg H, Mattsson N, et al. Detailed comparison of amyloid PET and CSF biomarkers for identifying early Alzheimer disease. Neurology 2015;85:1240-1249.

99. Klunk WE, Engler H, Nordberg A, et al. Imaging brain amyloid in Alzheimer's disease with Pittsburgh Compound-B. Ann Neurol 2004;55:306-319.

100. Rowe CC, Ellis KA, Rimajova M, et al. Amyloid imaging results from the Australian Imaging, Biomarkers and Lifestyle (AIBL) study of aging. Neurobiol Aging 2010;31:1275-1283.

101. Levine H, 3rd. Soluble multimeric Alzheimer beta(1-40) preamyloid complexes in dilute solution. Neurobiol Aging 1995;16: 755-764.

102. Mathis CA, Wang Y, Holt DP, Huang GF, Debnath ML, Klunk WE. Synthesis and evaluation of 11C-labeled 6-substituted 2arylbenzothiazoles as amyloid imaging agents. J Med Chem 2003;46:2740-2754.

103. Thal DR, Rub U, Orantes M, Braak H. Phases of A betadeposition in the human brain and its relevance for the development of AD. Neurology 2002;58:1791-1800.

104. Fagan AM, Mintun MA, Mach RH, et al. Inverse relation between in vivo amyloid imaging load and cerebrospinal fluid Abeta42 in humans. Ann Neurol 2006;59:512-519.

105. Grimmer T, Riemenschneider M, Forstl H, et al. Beta amyloid in Alzheimer's disease: increased deposition in brain is reflected in reduced concentration in cerebrospinal fluid. Biol Psychiatry 2009;65:927-934.

106. Zwan M, van Harten A, Ossenkoppele R, et al. Concordance between cerebrospinal fluid biomarkers and [11C]PIB PET in a memory clinic cohort. J Alzheimers Dis 2014;41:801-807.
107. Storandt M, Head D, Fagan AM, Holtzman DM, Morris JC. Toward a multifactorial model of Alzheimer disease. Neurobiol Aging 2012;33:2262-2271.

108. Forsberg A, Engler H, Almkvist O, et al. PET imaging of amyloid deposition in patients with mild cognitive impairment. Neurobiol Aging 2008;29:1456-1465.

109. Koivunen J, Scheinin N, Virta JR, et al. Amyloid PET imaging in patients with mild cognitive impairment: a 2-year follow-up study. Neurology 2011;76:1085-1090.

110. Cairns NJ, Ikonomovic MD, Benzinger T, et al. Absence of Pittsburgh compound B detection of cerebral amyloid beta in a patient with clinical, cognitive, and cerebrospinal fluid markers of Alzheimer disease: a case report. Arch Neurol 2009;66:15571562 .

111. Bacskai BJ, Frosch MP, Freeman SH, et al. Molecular imaging with Pittsburgh Compound B confirmed at autopsy: a case report. Arch Neurol 2007;64:431-434.

112. Ikonomovic MD, Klunk WE, Abrahamson EE, et al. Post-mortem correlates of in vivo PiB-PET amyloid imaging in a typical case of Alzheimer's disease. Brain 2008;131:1630-1645.

113. Kadir A, Marutle A, Gonzalez D, et al. Positron emission tomography imaging and clinical progression in relation to molecular pathology in the first Pittsburgh Compound B positron emission tomography patient with Alzheimer's disease. Brain 2011;134: 301-317.

114. Lockhart A, Lamb JR, Osredkar T, et al. PIB is a non-specific imaging marker of amyloid-beta (Abeta) peptide-related cerebral amyloidosis. Brain 2007;130:2607-2615.

115. Burack MA, Hartlein J, Flores HP, Taylor-Reinwald L, Perlmutter JS, Cairns NJ. In vivo amyloid imaging in autopsy-confirmed Parkinson disease with dementia. Neurology 2010;74:77-84.

116. Fodero-Tavoletti MT, Smith DP, McLean CA, et al. In vitro characterization of Pittsburgh compound-B binding to Lewy bodies. J Neurosci 2007;27:10365-10371.

117. Ikonomovic MD, Abrahamson EE, Price JC, et al. Early AD pathology in a [C-11]PiB-negative case: a PiB-amyloid imaging, biochemical, and immunohistochemical study. Acta Neuropathol 2012;123:433-447.

118. Kantarci K, Yang C, Schneider JA, et al. Antemortem amyloid imaging and beta-amyloid pathology in a case with dementia with Lewy bodies. Neurobiol Aging 2012;33:878-885.

119. Johnson KA, Gregas M, Becker JA, et al. Imaging of amyloid burden and distribution in cerebral amyloid angiopathy. Ann Neurol 2007;62:229-234.

120. Vinters HV, Gilbert JJ. Cerebral amyloid angiopathy: incidence and complications in the aging brain. II. The distribution of amyloid vascular changes. Stroke 1983;14:924-928.

121. Ly JV, Donnan GA, Villemagne VL, et al. 11C-PIB binding is increased in patients with cerebral amyloid angiopathy-related hemorrhage. Neurology 2010;74:487-493.

122. Sojkova J, Driscoll I, Iacono D, et al. In vivo fibrillar beta-amyloid detected using $[11 \mathrm{C}] \mathrm{PiB}$ positron emission tomography and neuropathologic assessment in older adults. Arch Neurol 2011;68: 232-240.

123. Ikonomovic MD, Klunk WE, Abrahamson EE, et al. Precuneus amyloid burden is associated with reduced cholinergic activity in Alzheimer disease. Neurology 2011;77:39-47.

124. Scheff SW, Price DA, Schmitt FA, Roberts KN, Ikonomovic MD, Mufson EJ. Synapse stability in the precuneus early in the progression of Alzheimer's disease. J Alzheimers Dis 2013;35:599609.

125. Beckett TL, Webb RL, Niedowicz DM, et al. Postmortem Pittsburgh Compound $\mathrm{B}$ ( $\mathrm{PiB}$ ) binding increases with Alzheimer's disease progression. J Alzheimers Dis 2012;32:127138. 
126. Niedowicz DM, Beckett TL, Matveev S, et al. Pittsburgh compound $\mathrm{B}$ and the postmortem diagnosis of Alzheimer disease. Ann Neurol 2012;72:564-570.

127. Landau SM, Horng A, Fero A, Jagust WJ, Alzheimer's Disease Neuroimaging I. Amyloid negativity in patients with clinically diagnosed Alzheimer disease and MCI. Neurology 2016;86: 1377-1385.

128. Mintun MA, Larossa GN, Sheline YI, et al. [11C]PIB in a nondemented population: potential antecedent marker of Alzheimer disease. Neurology 2006;67:446-452.

129. Mormino EC, Brandel MG, Madison CM, et al. Not quite PIBpositive, not quite PIB-negative: slight PIB elevations in elderly normal control subjects are biologically relevant. Neuroimage 2012;59:1152-1160.

130. Mormino EC, Kluth JT, Madison CM, et al. Episodic memory loss is related to hippocampal-mediated beta-amyloid deposition in elderly subjects. Brain 2009;132:1310-1323.

131. Reiman EM, Chen K, Liu X, et al. Fibrillar amyloid-beta burden in cognitively normal people at 3 levels of genetic risk for Alzheimer's disease. Proc Natl Acad Sci U S A 2009;106:68206825.

132. Villemagne VL, Pike KE, Darby D, et al. Abeta deposits in older non-demented individuals with cognitive decline are indicative of preclinical Alzheimer's disease. Neuropsychologia 2008;46:16881697.

133. Bennett DA, Schneider JA, Arvanitakis Z, et al. Neuropathology of older persons without cognitive impairment from two community-based studies. Neurology 2006;66:1837-1844.

134. Bennett DA, Wilson RS, Schneider JA, et al. Natural history of mild cognitive impairment in older persons. Neurology 2002;59: 198-205.

135. Mathis CA, Kuller LH, Klunk WE, et al. In vivo assessment of amyloid-beta deposition in nondemented very elderly subjects. Ann Neurol 2013;73:751-761.

136. Morris JC, Roe CM, Xiong C, et al. APOE predicts amyloid-beta but not tau Alzheimer pathology in cognitively normal aging. Ann Neurol 2010;67:122-131.

137. Kemppainen NM, Aalto S, Wilson IA, et al. PET amyloid ligand [11C]PIB uptake is increased in mild cognitive impairment. Neurology 2007;68:1603-1606.

138. Rowe CC, Ng S, Ackermann U, et al. Imaging beta-amyloid burden in aging and dementia. Neurology 2007;68:1718-1725.

139. Vlassenko AG, Mintun MA, Xiong C, et al. Amyloid-beta plaque growth in cognitively normal adults: longitudinal [11C]Pittsburgh compound B data. Ann Neurol 2011;70:857-861

140. Drzezga A, Grimmer T, Henriksen G, et al. Imaging of amyloid plaques and cerebral glucose metabolism in semantic dementia and Alzheimer's disease. Neuroimage 2008;39:619-633.

141. Grimmer T, Tholen S, Yousefi BH, et al. Progression of cerebral amyloid load is associated with the apolipoprotein E epsilon4 genotype in Alzheimer's disease. Biol Psychiatry 2010;68:879884

142. Rabinovici GD, Furst AJ, Alkalay A, et al. Increased metabolic vulnerability in early-onset Alzheimer's disease is not related to amyloid burden. Brain 2010;133:512-528.

143. Perez-Nievas BG, Stein TD, Tai HC, et al. Dissecting phenotypic traits linked to human resilience to Alzheimer's pathology. Brain 2013;136:2510-2526.

144. Resnick SM, Sojkova J, Zhou Y, et al. Longitudinal cognitive decline is associated with fibrillar amyloid-beta measured by [11C]PiB. Neurology 2010;74:807-815.

145. Storandt M, Mintun MA, Head D, Morris JC. Cognitive decline and brain volume loss as signatures of cerebral amyloid-beta peptide deposition identified with Pittsburgh compound B: cognitive decline associated with Abeta deposition. Arch Neurol 2009;66: 1476-1481.
146. Villemagne VL, Pike KE, Chetelat G, et al. Longitudinal assessment of Abeta and cognition in aging and Alzheimer disease. Ann Neurol 2011;69:181-192.

147. Lowe VJ, Kemp BJ, Jack CR, Jr., et al. Comparison of 18F-FDG and PiB PET in cognitive impairment. J Nucl Med 2009;50:878886.

148. Pike KE, Savage G, Villemagne VL, et al. Beta-amyloid imaging and memory in non-demented individuals: evidence for preclinical Alzheimer's disease. Brain 2007;130:2837-2844.

149. Landau SM, Thomas BA, Thurfjell L, et al. Amyloid PET imaging in Alzheimer's disease: a comparison of three radiotracers. Eur J Nucl Med Mol Imaging 2014;41:1398-1407.

150. Mason NS, Mathis CA, Klunk WE. Positron emission tomography radioligands for in vivo imaging of Abeta plaques. J Labelled Comp Radiopharm 2013;56:89-95.

151. Heurling K, Leuzy A, Zimmer ER, Lubberink M, Nordberg A. Imaging beta-amyloid using [(18)F]flutemetamol positron emission tomography: from dosimetry to clinical diagnosis. Eur J Nucl Med Mol Imaging 2016;43:362-373.

152. Nelissen N, Van Laere K, Thurfjell L, et al. Phase 1 study of the Pittsburgh compound $\mathrm{B}$ derivative $18 \mathrm{~F}$-flutemetamol in healthy volunteers and patients with probable Alzheimer disease. J Nuclear Med 2009;50:1251-1259.

153. Vandenberghe R, Van Laere K, Ivanoiu A, et al. 18F-flutemetamol amyloid imaging in Alzheimer disease and mild cognitive impairment: a phase 2 trial. Ann Neurol 2010;68:319-329.

154. Curtis C, Gamez JE, Singh U, et al. Phase 3 trial of flutemetamol labeled with radioactive fluorine 18 imaging and neuritic plaque density. JAMA Neurol 2015;72:287-294.

155. Trembath L, Newell M, Devous MD, Sr. Technical considerations in brain amyloid PET imaging with 18F-florbetapir. J Nucl Med Technol 2015;43:175-184.

156. Lister-James J, Pontecorvo MJ, Clark C, et al. Florbetapir f-18: a histopathologically validated beta-amyloid positron emission tomography imaging agent. Semin Nucl Med 2011;41:300-304.

157. Wong DF, Rosenberg PB, Zhou Y, et al. In vivo imaging of amyloid deposition in Alzheimer disease using the radioligand $18 \mathrm{~F}$ AV-45 (florbetapir [corrected] F 18). J Nuclear Med 2010;51:913920.

158. Fleisher AS, Chen K, Liu X, et al. Using positron emission tomography and florbetapir F18 to image cortical amyloid in patients with mild cognitive impairment or dementia due to Alzheimer disease. Arch Neurol 2011;68:1404-1411.

159. Clark CM, Schneider JA, Bedell BJ, et al. Use of florbetapir-PET for imaging beta-amyloid pathology. JAMA 2011;305:275-283.

160. Camus V, Payoux P, Barre L, et al. Using PET with 18F-AV-45 (florbetapir) to quantify brain amyloid load in a clinical environment. Eur J Nucl Med Mol Imaging 2012;39:621-631.

161. Richards D, Sabbagh MN. Florbetaben for PET imaging of betaamyloid plaques in the brain. Neurol Ther 2014;3:79-88.

162. Rowe CC, Ackerman U, Browne W, et al. Imaging of amyloid beta in Alzheimer's disease with 18F-BAY94-9172, a novel PET tracer: proof of mechanism. Lancet Neurol 2008;7:129-135.

163. Villemagne VL, Ong K, Mulligan RS, et al. Amyloid imaging with (18)F-florbetaben in Alzheimer disease and other dementias. J Nucl Med 2011;52:1210-217.

164. Barthel H, Gertz HJ, Dresel S, et al. Cerebral amyloid-beta PET with florbetaben $(18 \mathrm{~F})$ in patients with Alzheimer's disease and healthy controls: a multicentre phase 2 diagnostic study. Lancet Neurol 2011;10:424-435.

165. Barthel H, Luthardt J, Becker G, et al. Individualized quantification of brain beta-amyloid burden: results of a proof of mechanism phase 0 florbetaben PET trial in patients with Alzheimer's disease and healthy controls. Eur J Nucl Med Mol Imaging 2011;38:17021714 . 
166. Sabri O, Sabbagh MN, Seibyl J, et al. Florbetaben PET imaging to detect amyloid beta plaques in Alzheimer's disease: phase 3 study. Alzheimers Dement 2015;11:964-974.

167. Cohen AD, Klunk WE. Early detection of Alzheimer's disease using PiB and FDG PET. Neurobiol Dis 2014;72:117-122.

168. Foster NL, Heidebrink JL, Clark CM, et al. FDG-PET improves accuracy in distinguishing frontotemporal dementia and Alzheimer's disease. Brain 2007;130:2616-2635.

169. Friedland RP, Budinger TF, Ganz E, et al. Regional cerebral metabolic alterations in dementia of the Alzheimer type: positron emission tomography with [18F]fluorodeoxyglucose. J Comput Assist Tomogr 1983;7:590-598.

170. Jagust W, Reed B, Mungas D, Ellis W, Decarli C. What does fluorodeoxyglucose PET imaging add to a clinical diagnosis of dementia? Neurology 2007;69:871-877.

171. Reiman EM, Caselli RJ, Yun LS, et al. Preclinical evidence of Alzheimer's disease in persons homozygous for the epsilon 4 allele for apolipoprotein E. N Engl J Med 1996;334:752-758.

172. Small GW, Ercoli LM, Silverman DH, et al. Cerebral metabolic and cognitive decline in persons at genetic risk for Alzheimer's disease. Proc Natl Acad Sci U S A 2000;97:6037-6042.

173. Arnaiz E, Jelic V, Almkvist O, et al. Impaired cerebral glucose metabolism and cognitive functioning predict deterioration in mild cognitive impairment. Neuroreport 2001;12:851-855.

174. Chetelat G, Desgranges B, de la Sayette V, et al. Dissociating atrophy and hypometabolism impact on episodic memory in mild cognitive impairment. Brain 2003;126:1955-1967.

175. Chetelat G, Desgranges B, de la Sayette V, Viader F, Eustache F, Baron JC. Mild cognitive impairment: can FDG-PET predict who is to rapidly convert to Alzheimer's disease? Neurology 2003;60: 1374-1377.

176. Del Sole A, Clerici F, Chiti A, et al. Individual cerebral metabolic deficits in Alzheimer's disease and amnestic mild cognitive impairment: an FDG PET study. Eur J Nucl Med Mol Imaging 2008;35:1357-1366.

177. Garibotto V, Borroni B, Kalbe E, et al. Education and occupation as proxies for reserve in aMCI converters and AD: FDG-PET evidence. Neurology 2008;71:1342-1349.

178. Mevel K, Desgranges B, Baron JC, et al. Detecting hippocampal hypometabolism in Mild Cognitive Impairment using automatic voxel-based approaches. Neuroimage 2007;37:18-25.

179. Mosconi L, De Santi S, Li Y, et al. Visual rating of medial temporal lobe metabolism in mild cognitive impairment and Alzheimer's disease using FDG-PET. Eur J Nucl Med Mol Imaging 2006;33: 210-221.

180. Perneczky R, Hartmann J, Grimmer T, Drzezga A, Kurz A. Cerebral metabolic correlates of the clinical dementia rating scale in mild cognitive impairment. J Geriatr Psychiatry Neurol 2007;20:84-88

181. Anchisi D, Borroni B, Franceschi M, et al. Heterogeneity of brain glucose metabolism in mild cognitive impairment and clinical progression to Alzheimer disease. Arch Neurol 2005;62:17281733

182. Drzezga A, Grimmer T, Riemenschneider M, et al. Prediction of individual clinical outcome in MCI by means of genetic assessment and (18)F-FDG PET. J Nuclear Med 2005;46:1625-1632.

183. Mosconi L, Perani D, Sorbi S, et al. MCI conversion to dementia and the APOE genotype: a prediction study with FDG-PET. Neurology 2004;63:2332-2340.

184. Li Y, Rinne JO, Mosconi L, et al. Regional analysis of FDG and PIB-PET images in normal aging, mild cognitive impairment, and Alzheimer's disease. Eur J Nucl Med Mol Imaging 2008;35:2169-2181.

185. Cohen AD, Price JC, Weissfeld LA, et al. Basal cerebral metabolism may modulate the cognitive effects of Abeta in mild cognitive impairment: an example of brain reserve. J Neurosci 2009;29: 14770-14778.

186. Furst AJ, Rabinovici GD, Rostomian AH, et al. Cognition, glucose metabolism and amyloid burden in Alzheimer's disease. Neurobiol Aging 2012;33:215-225.

187. Apostolova LG, Dutton RA, Dinov ID, et al. Conversion of mild cognitive impairment to Alzheimer disease predicted by hippocampal atrophy maps. Arch Neurol 2006;63:693-699.

188. Becker JT, Davis SW, Hayashi KM, et al. Three-dimensional patterns of hippocampal atrophy in mild cognitive impairment. Arch Neurol 2006;63:97-101.

189. Grundman M, Sencakova D, Jack CR, Jr., et al. Brain MRI hippocampal volume and prediction of clinical status in a mild cognitive impairment trial. J Mol Neurosci 2002;19:23-27.

190. Moretti DV, Miniussi C, Frisoni GB, et al. Hippocampal atrophy and EEG markers in subjects with mild cognitive impairment. Clinical Neurophysiol 2007;118:2716-2729.

191. Morra JH, Tu Z, Apostolova LG, et al. Automated mapping of hippocampal atrophy in 1-year repeat MRI data from 490 subjects with Alzheimer's disease, mild cognitive impairment, and elderly controls. NeuroImage 2009;45(1 Suppl.):S3-S15.

192. Chetelat G, Fouquet M, Kalpouzos G, et al. Three-dimensional surface mapping of hippocampal atrophy progression from $\mathrm{MCl}$ to $\mathrm{AD}$ and over normal aging as assessed using voxel-based morphometry. Neuropsychologia 2008;46:1721-1731.

193. deToledo-Morrell L, Stoub TR, Bulgakova M, et al. MRI-derived entorhinal volume is a good predictor of conversion from MCI to AD. Neurobiol Aging 2004;25:1197-1203.

194. Devanand DP, Pradhaban G, Liu X, et al. Hippocampal and entorhinal atrophy in mild cognitive impairment: prediction of Alzheimer disease. Neurology 2007;68:828-836.

195. Jack CR, Jr., Petersen RC, Xu Y, et al. Rates of hippocampal atrophy correlate with change in clinical status in aging and AD. Neurology 2000;55:484-489.

196. Jack CR, Jr., Petersen RC, Xu YC, et al. Prediction of AD with MRI-based hippocampal volume in mild cognitive impairment. Neurology 1999;52:1397-1403.

197. Wang H, Golob E, Bert A, et al. Alterations in regional brain volume and individual MRI-guided perfusion in normal control, stable mild cognitive impairment, and MCI-AD converter. J Geriatr Psychiatry Neurol 2009;22:35-45.

198. Risacher SL, Saykin AJ, West JD, et al. Baseline MRI predictors of conversion from MCI to probable $\mathrm{AD}$ in the $\mathrm{ADNI}$ cohort. Curr Alzheimer Res 2009;6:347-361.

199. Risacher SL, Shen L, West JD, et al. Longitudinal MRI atrophy biomarkers: relationship to conversion in the ADNI cohort. Neurobiol Aging 2010;31:1401-1418.

200. Schuff N, Tosun D, Insel PS, et al. Nonlinear time course of brain volume loss in cognitively normal and impaired elders. Neurobiol Aging 2012;33:845-855.

201. Archer HA, Edison P, Brooks DJ, et al. Amyloid load and cerebral atrophy in Alzheimer's disease: an 11C-PIB positron emission tomography study. Ann Neurol 2006;60:145-147.

202. Chetelat G, Villemagne VL, Bourgeat P, et al. Relationship between atrophy and beta-amyloid deposition in Alzheimer disease. Ann Neurol 2010;67:317-324.

203. Fotenos AF, Mintun MA, Snyder AZ, Morris JC, Buckner RL. Brain volume decline in aging: evidence for a relation between socioeconomic status, preclinical Alzheimer disease, and reserve. Arch Neurol 2008;65:113-120.

204. Frisoni GB, Lorenzi M, Caroli A, Kemppainen N, Nagren K, Rinne JO. In vivo mapping of amyloid toxicity in Alzheimer disease. Neurology 2009;72:1504-1511.

205. Arriagada PV, Growdon JH, Hedley-Whyte ET, Hyman BT. Neurofibrillary tangles but not senile plaques parallel duration 
and severity of Alzheimer's disease. Neurology 1992;42:631639.

206. Villemagne VL. Amyloid imaging: past, present and future perspectives. Ageing Res Rev 2016;30:95-106.

207. Harada R, Okamura N, Furumoto S, et al. Characteristics of tau and its ligands in PET imaging. Biomolecules 2016;6:7.

208. Chiotis K, Saint-Aubert L, Savitcheva I, et al. Imaging in-vivo tau pathology in Alzheimer's disease with THK5317 PET in a multimodal paradigm. Eur J Nucl Med Mol Imaging 2016;43:16861699.

209. Harada R, Okamura N, Furumoto S, et al. Comparison of the binding characteristics of [18F]THK-523 and other amyloid imaging tracers to Alzheimer's disease pathology. Eur J Nucl Med Mol Imaging 2013;40:125-132.

210. Lemoine L, Saint-Aubert L, Marutle A, et al. Visualization of regional tau deposits using (3)H-THK5117 in Alzheimer brain tissue. Acta Neuropathol Commun 2015;3:40.

211. Okamura N, Furumoto S, Fodero-Tavoletti MT, et al. Noninvasive assessment of Alzheimer's disease neurofibrillary pathology using 18F-THK5105 PET. Brain 2014;137:1762-1771.

212. Villemagne VL, Furumoto S, Fodero-Tavoletti MT, et al. In vivo evaluation of a novel tau imaging tracer for Alzheimer's disease. Eur J Nucl Med Mol Imaging 2014;41:816-826.

213. Harada R, Okamura N, Furumoto S, et al. [(18)F]THK-5117 PET for assessing neurofibrillary pathology in Alzheimer's disease. Eur J Nucl Med Mol Imaging 2015;42:1052-1061.

214. Harada R, Okamura N, Furumoto S, et al. 18F-THK5351: a novel PET radiotracer for imaging neurofibrillary pathology in Alzheimer disease. J Nucl Med 2016;57:208-214.

215. Ishiki A, Okamura N, Furukawa K, et al. Longitudinal assessment of tau pathology in patients with Alzheimer's disease using [18F]THK-5117 positron emission tomography. PLOS ONE 2015; 10:e 0140311.

216. Lockhart SN, Baker SL, Okamura N, et al. Dynamic PET measures of tau accumulation in cognitively normal older adults and Alzheimer's disease patients measured using [18F] THK-5351. PLOS ONE 2016;11:e0158460.

217. Tago T, Furumoto S, Okamura N, et al. Structure-activity relationship of 2-arylquinolines as PET imaging tracers for tau pathology in Alzheimer disease. J Nuclear Med 2016;57:608-614.

218. Maruyama M, Shimada H, Suhara T, et al. Imaging of tau pathology in a tauopathy mouse model and in Alzheimer patients compared to normal controls. Neuron 2013;79:1094-1108.

219. Kimura $Y$, Ichise $M$, Ito $H$, et al. PET quantification of tau pathology in human brain with 11C-PBB3. J Nucl Med 2015;56:13591365.

220. Hashimoto H, Kawamura K, Igarashi N, et al. Radiosynthesis, photoisomerization, biodistribution, and metabolite analysis of $11 \mathrm{C}-\mathrm{PBB} 3$ as a clinically useful PET probe for imaging of tau pathology. J Nucl Med 2014;55:1532-1538.

221. Chien DT, Bahri S, Szardenings AK, et al. Early clinical PET imaging results with the novel PHF-tau radioligand [F-18]-T807. J Alzheimers Dis 2013;34:457-468.

222. Chien DT, Szardenings AK, Bahri S, et al. Early clinical PET imaging results with the novel PHF-tau radioligand [F18]-T808. J Alzheimers Dis 2014;38:171-184.

223. Declercq L, Celen S, Lecina J, et al. Comparison of new tau PETtracer candidates with $[18 \mathrm{~F}] \mathrm{T} 808$ and $[18 \mathrm{~F}] \mathrm{T} 807$. Mol Imaging 2016;15.

224. Holt DP, Ravert HT, Dannals RF. Synthesis and quality control of [(18) F]T807 for tau PET imaging. J Labelled Comp Radiopharm 2016;59:411-415.

225. Walji AM, Hostetler ED, Selnick H, et al. Discovery of 6-(fluoro(18)F)-3-(1H-pyrrolo[2,3-c]pyridin-1-yl)isoquinolin-5-amine ([(18)F]-MK-6240): a positron emission tomography (PET) imaging agent for quantification of neurofibrillary tangles (NFTs). J Med Chem 2016;59:4778-4789.

226. Braak H, Braak E. Neuropathological stageing of Alzheimerrelated changes. Acta Neuropathol 1991;82:239-259.

227. Xia CF, Arteaga J, Chen G, et al. [(18)F]T807, a novel tau positron emission tomography imaging agent for Alzheimer's disease. Alzheimers Dement 2013;9:666-676.

228. Chhatwal JP, Schultz AP, Marshall GA, et al. Temporal T807 binding correlates with CSF tau and phospho-tau in normal elderly. Neurology 2016;87:920-926.

229. Cho H, Choi JY, Hwang MS, et al. Tau PET in Alzheimer disease and mild cognitive impairment. Neurology 2016;87:375-383.

230. Wang L, Benzinger TL, Su Y, et al. Evaluation of tau imaging in staging Alzheimer disease and revealing interactions between beta-amyloid and tauopathy. JAMA Neurol 2016;73:1070-1077.

231. Marquie M, Normandin MD, Vanderburg CR, et al. Validating novel tau positron emission tomography tracer [F-18]-AV-1451 (T807) on postmortem brain tissue. Ann Neurol 2015;78:787-800.

232. Lowe VJ, Curran G, Fang P, et al. An autoradiographic evaluation of AV-1451 Tau PET in dementia. Acta Neuropathol Commun 2016;4:58

233. Sander K, Lashley T, Gami P, et al. Characterization of tau positron emission tomography tracer $[18 \mathrm{~F}] \mathrm{AV}-1451$ binding to postmortem tissue in Alzheimer's disease, primary tauopathies, and other dementias. Alzheimers Dement 2016 Feb 15 [Epub ahead of print].

234. Smith R, Puschmann A, Scholl M, et al. 18F-AV-1451 tau PET imaging correlates strongly with tau neuropathology in MAPT mutation carriers. Brain 2016;139:2372-2379.

235. Villemagne VL, Okamura N. Tau imaging in the study of ageing, Alzheimer's disease, and other neurodegenerative conditions. Curr Opin Neurobiol 2016;36:43-51.

236. Irizarry MC. Biomarkers of Alzheimer disease in plasma. NeuroRx 2004;1:226-234.

237. Graff-Radford NR, Crook JE, Lucas J, et al. Association of low plasma Abeta42/Abeta40 ratios with increased imminent risk for mild cognitive impairment and Alzheimer disease. Arch Neurol 2007;64:354-362.

238. Mayeux R, Honig LS, Tang MX, et al. Plasma A[beta $] 40$ and $\mathrm{A}[$ beta]42 and Alzheimer's disease: relation to age, mortality, and risk. Neurology 2003;61:1185-1190.

239. Pomara N, Willoughby LM, Sidtis JJ, Mehta PD. Selective reductions in plasma Abeta 1-42 in healthy elderly subjects during longitudinal follow-up: a preliminary report. Am J Geriatr Psychiatry 2005;13:914-917.

240. Zetterberg H, Wilson D, Andreasson U, et al. Plasma tau levels in Alzheimer's disease. Alzheimers Res Ther 2013;5:9.

241. Fiandaca MS, Kapogiannis D, Mapstone M, et al. Identification of preclinical Alzheimer's disease by a profile of pathogenic proteins in neurally derived blood exosomes: a case-control study. Alzheimers Dement 2015;11:600-607 e1.

242. Ray S, Britschgi M, Herbert C, et al. Classification and prediction of clinical Alzheimer's diagnosis based on plasma signaling proteins. Nat Med 2007;13:1359-1362.

243. Buerger K, Frisoni G, Uspenskaya O, et al. Validation of Alzheimer's disease CSF and plasma biological markers: the multicentre reliability study of the pilot European Alzheimer's Disease Neuroimaging Initiative (E-ADNI). Exp Gerontol 2009;44:579-585.

244. O'Bryant SE, Xiao G, Barber R, et al. A blood-based screening tool for Alzheimer's disease that spans serum and plasma: findings from TARC and ADNI. PLOS ONE 2011;6:e28092.

245. Doecke JD, Laws SM, Faux NG, et al. Blood-based protein biomarkers for diagnosis of Alzheimer disease. Arch Neurol 2012;69: 1318-1325. 
246. Hu WT, Holtzman DM, Fagan AM, et al. Plasma multianalyte profiling in mild cognitive impairment and Alzheimer disease. Neurology 2012;79:897-905.

247. Zhao X, Lejnine S, Spond J, et al. A candidate plasma protein classifier to identify Alzheimer's disease. J Alzheimers Dis 2015;43:549-563.

248. Mapstone M, Cheema AK, Fiandaca MS, et al. Plasma phospholipids identify antecedent memory impairment in older adults. Nat Med 2014;20:415-418

249. Kiddle SJ, Steves CJ, Mehta M, et al. Plasma protein biomarkers of Alzheimer's disease endophenotypes in asymptomatic older twins: early cognitive decline and regional brain volumes. Transl Psychiatry 2015;5:e584.

250. O'Bryant SE, Gupta V, Henriksen K, et al. Guidelines for the standardization of preanalytic variables for blood-based biomarker studies in Alzheimer's disease research. Alzheimers Dement 2015;11:549-560.

251. DiFrancesco JC, Longoni M, Piazza F. Anti-Abeta autoantibodies in amyloid related imaging abnormalities (ARIA): candidate biomarker for immunotherapy in Alzheimer's disease and cerebral amyloid angiopathy. Front Neurol 2015;6:207.

252. Hyman BT, Smith C, Buldyrev I, et al. Autoantibodies to amyloidbeta and Alzheimer's disease. Ann Neurol 2001;49:808-810.

253. Schneider P, Hampel H, Buerger K. Biological marker candidates of Alzheimer's disease in blood, plasma, and serum. CNS Neurosci Ther 2009;15:358-374.

254. Hock C, Konietzko U, Streffer JR, et al. Antibodies against betaamyloid slow cognitive decline in Alzheimer's disease. Neuron 2003;38:547-554.

255. Dodel RC, Du Y, Depboylu C, et al. Intravenous immunoglobulins containing antibodies against beta-amyloid for the treatment of Alzheimer's disease. J Neurol Neurosurg Psychiatry 2004;75: 1472-1474.

256. Holmes C, Boche D, Wilkinson D, et al. Long-term effects of Abeta42 immunisation in Alzheimer's disease: follow-up of a randomised, placebo-controlled phase I trial. Lancet 2008;372: 216-223.

257. Fu HJ, Liu B, Frost JL, Lemere CA. Amyloid-beta immunotherapy for Alzheimer's disease. CNS Neurol Disord Drug Targets 2010;9:197-206.

258. Reardon S. Antibody drugs for Alzheimer's show glimmers of promise. Nature 2015;523:509-510.

259. Sevigny J, Chiao P, Bussiere T, et al. The antibody aducanumab reduces Abeta plaques in Alzheimer's disease. Nature 2016;537: $50-56$.

260. Colasanti T, Barbati C, Rosano G, Malorni W, Ortona E. Autoantibodies in patients with Alzheimer's disease: pathogenetic role and potential use as biomarkers of disease progression. Autoimmun Rev 2010;9:807-811.

261. DeMarshall C, Sarkar A, Nagele EP, et al. Utility of autoantibodies as biomarkers for diagnosis and staging of neurodegenerative diseases. Int Rev Neurobiol 2015;122:1-51.

262. Davydova TV, Voskresenskaya NI, Fomina VG, Vetrile LA, Doronina OA. Induction of autoantibodies to glutamate in patients with Alzheimer's disease. Bull Exp Biol Med 2007;143:182-183.

263. Gruden MA, Davidova TB, Malisauskas M, et al. Differential neuroimmune markers to the onset of Alzheimer's disease neurodegeneration and dementia: autoantibodies to Abeta((25-35)) oligomers, S100b and neurotransmitters. J Neuroimmunol 2007;186: 181-192.

264. Hempel P, Heinig B, Jerosch C, et al. Immunoadsorption of agonistic autoantibodies against alpha1-adrenergic receptors in patients with mild to moderate dementia. Ther Apher Dial 2016 Apr 20 [Epub ahead of print].

265. Karczewski P, Hempel P, Kunze R, Bimmler M. Agonistic autoantibodies to the alpha(1) -adrenergic receptor and the beta(2) - adrenergic receptor in Alzheimer's and vascular dementia. Scand J Immunol 2012;75:524-530.

266. Busse S, Brix B, Kunschmann R, Bogerts B, Stoecker W, Busse M. N-methyl-d-aspartate glutamate receptor (NMDA-R) antibodies in mild cognitive impairment and dementias. Neurosci Res 2014;85:58-64.

267. Doss S, Wandinger KP, Hyman BT, et al. High prevalence of NMDA receptor $\operatorname{IgA} / \operatorname{IgM}$ antibodies in different dementia types. Ann Clin Transl Neurol 2014;1:822-832.

268. Pruss H, Holtje M, Maier N, et al. IgA NMDA receptor antibodies are markers of synaptic immunity in slow cognitive impairment. Neurology 2012;78:1743-1753.

269. Koval L, Lykhmus O, Kalashnyk O, et al. The presence and origin of autoantibodies against alpha4 and alpha7 nicotinic acetylcholine receptors in the human blood: possible relevance to Alzheimer's pathology. J Alzheimers Dis 2011;25:747-761.

270. Moon J, Lee ST, Shin JW, et al. Non-stiff anti-amphiphysin syndrome: clinical manifestations and outcome after immunotherapy. J Neuroimmunol 2014;274:209-214.

271. Nagele E, Han M, Demarshall C, Belinka B, Nagele R. Diagnosis of Alzheimer's disease based on disease-specific autoantibody profiles in human sera. PLOS ONE 2011;6:e23112.

272. Yokoyama JS, Wang Y, Schork AJ, et al. Association between genetic traits for immune-mediated diseases and Alzheimer disease. JAMA Neurol 2016;73:691-697.

273. Mecocci P, Parnetti L, Romano G, et al. Serum anti-GFAP and anti-S100 autoantibodies in brain aging, Alzheimer's disease and vascular dementia. J Neuroimmunol 1995;57:165-170.

274. Delunardo F, Margutti P, Pontecorvo S, et al. Screening of a microvascular endothelial cDNA library identifies rabaptin 5 as a novel autoantigen in Alzheimer's disease. J Neuroimmunol 2007;192:105-112.

275. Giil LM, Kristoffersen EK, Vedeler CA, et al. Autoantibodies toward the angiotensin 2 type 1 receptor: a novel autoantibody in Alzheimer's disease. J Alzheimers Dis 2015;47:523-529.

276. Ariga T, Kubota M, Nakane M, Oguro K, Yu RK, Ando S. AntiChol-1 antigen, GQ1balpha, antibodies are associated with Alzheimer's disease. PLOS ONE 2013;8:e63326.

277. Eriksson UK, Sjoberg BG, Bennet AM, de Faire U, Pedersen NL, Frostegard J. Low levels of antibodies against phosphorylcholine in Alzheimer's disease. J Alzheimers Dis 2010;21:577-584.

278. Kankaanpaa J, Turunen SP, Moilanen V, Horkko S, Remes AM. Cerebrospinal fluid antibodies to oxidized LDL are increased in Alzheimer's disease. Neurobiol Dis 2009;33:467-472.

279. McIntyre JA, Ramsey CJ, Gitter BD, et al. Antiphospholipid autoantibodies as blood biomarkers for detection of early stage Alzheimer's disease. Autoimmunity 2015;48:344-351.

280. McIntyre JA, Wagenknecht DR, Ramsey CJ. Redox-reactive antiphospholipid antibody differences between serum from Alzheimer's patients and age-matched controls. Autoimmunity 2009;42:646-652.

281. Miura Y, Miyaji K, Chai YL, Chen CL, Lai MK, Yuki N. Autoantibodies to GM1 and GQ1balpha are not biological markers of Alzheimer's disease. J Alzheimers Dis 2014;42:11651169.

282. Mor F, Izak M, Cohen IR. Identification of aldolase as a target antigen in Alzheimer's disease. J Immunol 2005;175:3439-3445.

283. Vacirca D, Barbati C, Scazzocchio B, et al. Anti-ATP synthase autoantibodies from patients with Alzheimer's disease reduce extracellular HDL level. J Alzheimers Dis 2011;26:441-445.

284. Vacirca D, Delunardo F, Matarrese P, et al. Autoantibodies to the adenosine triphosphate synthase play a pathogenetic role in Alzheimer's disease. Neurobiol Aging 2012;33:753-766.

285. Jove M, Portero-Otin M, Naudi A, Ferrer I, Pamplona R. Metabolomics of human brain aging and age-related neurodegenerative diseases. J Neuropathol Exp Neurol 2014;73:640-6457. 
286. Allinquant B, Clamagirand C, Potier MC. Role of cholesterol metabolism in the pathogenesis of Alzheimer's disease. Curr Opin Clin Nutr Metab Care 2014;17:319-323.

287. Wood JM, Gupta S. Vitamin D and neurocognitive disorder due to Alzheimer's disease: a review of the literature. Ann Clin Psychiatry 2015;27:206-212. P
288. Zaman Z, Roche S, Fielden P, Frost PG, Niriella DC, Cayley AC. Plasma concentrations of vitamins $\mathrm{A}$ and $\mathrm{E}$ and carotenoids in Alzheimer's disease. Age Ageing 1992;21:91-94.

289. Fiandaca MS, Zhong X, Cheema AK, et al. Plasma 24-metabolite panel predicts preclinical transition to clinical stages of Alzheimer's disease. Front Neurol 2015;6:237. 